Illinois State University

ISU ReD: Research and eData

Theses and Dissertations

$3-31-2021$

\title{
Sleep Quality And Prevalence Of Anxiety And Depression In Young Adults With Concussion History
}

Jessica Barrack

Illinois State University, jsbarra@ilstu.edu

Follow this and additional works at: https://ir.library.illinoisstate.edu/etd

Part of the Kinesiology Commons

\section{Recommended Citation}

Barrack, Jessica, "Sleep Quality And Prevalence Of Anxiety And Depression In Young Adults With Concussion History" (2021). Theses and Dissertations. 1351.

https://ir.library.illinoisstate.edu/etd/1351

This Thesis is brought to you for free and open access by ISU ReD: Research and eData. It has been accepted for inclusion in Theses and Dissertations by an authorized administrator of ISU ReD: Research and eData. For more information, please contact ISUReD@ilstu.edu. 


\title{
SLEEP QUALITY AND PREVALENCE OF ANXIETY AND DEPRESSION IN YOUNG ADULTS WITH CONCUSSION HISTORY
}

\author{
JESSICA S. BARRACK
}

\section{Pages}

Background: Concussions are a growing public health concern, and emerging long-term health risks may negatively impact an individual's quality of life. With concussions, there can be a multitude of signs and symptoms, but frequent long-term sequelae of concussions including mood disturbances (e.g. trait anxiety and depression) and sleep disturbances (e.g. difficulties initiating and maintaining sleep) are given less attention. Few clinicians address mood and sleep disturbances in their concussion assessment and management plan, potentially placing individuals at risk for prolonged disturbances beyond recovery. Purpose: To examine the relationship between sleep disturbances (sleep quality) and mood disturbances (trait anxiety and depression) in healthy young adults with and without a history of concussions. Methods: Healthy young adults $(\mathrm{n}=436$ ) from 3 universities across the country completed a one-time, 15-20-minute anonymous survey administered via Qualtrics. Survey components consisted of demographic information, concussion history, two mood disturbance questionnaires (State-Trait Anxiety Inventory and Beck Depression Inventory) and two sleep quality questionnaires (Pittsburgh Sleep Quality Index (PQSI) and Insomnia Severity Index (ISI)). Exclusion criteria consisted of having suffered a concussion or traumatic brain injury within the past 6 months, history of cancerous brain tumors, and diagnosed with post-traumatic stress disorder, schizophrenia, or bipolar disorder. Structural equation modeling (SEM) was used as the primary statistical analysis for trait anxiety (model 1) and depression (model 2). Results: Concussion history has an indirect 
relationship with trait anxiety and depression, where sleep quality mediates this relationship. Mediation analysis indicated no direct relationship of concussion history with anxiety and depression, but a significant direct pathway from concussion history to sleep quality ( $\beta=0.015$, $\mathrm{SE}=0.005, \mathrm{p}<0.001)$ and from sleep quality to trait anxiety $(\beta=0.168, \mathrm{SE}=0.015 \mathrm{p}<0.001)$ and depression $(\beta=0.186, \mathrm{SE}=0.016 \mathrm{p}<0.001)$. Model 1 accounted for a significant amount of variance in concussion history $(7.9 \%)$ and sleep quality $(37.3 \%$,$) on trait anxiety. Model 2$ accounted for a significant variance for concussion history (7.7\%) and sleep quality (36.6\%) on depression. Conclusion: Concussion history may not influence trait anxiety and depression directly, but it may have an influence through an indirect pathway of sleep quality. Our preliminary findings demonstrate the importance of examining trait anxiety, depression, and sleep disturbances together within individuals with a history of concussion and these components collectively may be important to include as part of baseline screening and in the evaluation and management of concussion.

KEYWORDS: Concussion; Mild Traumatic Brain Injury; Mood Disturbances; Sleep Disturbances; Trait Anxiety 


\title{
SLEEP QUALITY AND PREVALENCE OF ANXIETY AND DEPRESSION IN YOUNG ADULTS WITH CONCUSSION HISTORY
}

\author{
JESSICA S. BARRACK
}

A Thesis Submitted in Partial Fulfillment of the Requirements for the Degree of

\section{MASTER OF SCIENCE}

School of Kinesiology and Recreation

\section{ILLINOIS STATE UNIVERSITY}


(C) 2021 Jessica Barrack 


\title{
SLEEP QUALITY AND PREVALENCE OF ANXIETY AND DEPRESSION IN YOUNG ADULTS WITH CONCUSSION HISTORY
}

\author{
JESSICA S. BARRACK
}

COMMITTEE MEMBERS:

Nicole L. Hoffman, Chair

Noelle M. Selkow 


\section{ACKNOWLEDGMENTS}

First and foremost, I would like to express my deepest appreciation and gratitude to my advisor, Dr. Nicole Hoffman. Without her this thesis would not have been possible without her unparalleled support and her profound belief in this topic and in me. She has gone above and beyond what most advisors would do, and I am extremely grateful for her throughout, not just graduate school, but undergraduate as well. I also would like to express my sincere thanks to my other committee member, Dr. Noelle Selkow for her insightful suggestions and extensive knowledge that cannot be underestimated. Additionally, I would like to acknowledge the assistance of Melissa Joyce McGranahan from the University of Georgia in Athens; thank you for your invaluable contribution and guidance especially with our statistical analysis.

Furthermore, I owe the utmost gratitude to my research assistant, Andrea Cañas, as there is no one else I would have rather assist me in finding research studies and organizing hundreds of data with. Lastly, I would like to thank my friends, family, and the love of my life for without their unwavering support, I would not be where I am today. From the bottom of my heart, thank you all for your encouragement throughout this incredible journey.

J.S.B. 


\section{CONTENTS}

Page

ACKNOWLEDGMENTS

TABLES

FIGURES

CHAPTER I: INTRODUCTION 1

CHAPTER II: REVIEW OF LITERATURE

Brain Anatomy

$\begin{array}{ll}\text { Anxiety } & 6\end{array}$

$\begin{array}{ll}\text { Depression } & 8\end{array}$

Mood, Anxiety, Depression, and Concussion 9

Mood, Anxiety, and Depression with History of Concussion 9

Mood, Anxiety, and Depression with History of Multiple Concussions 11

$\begin{array}{ll}\text { Sleep Quality } & 12\end{array}$

Sleep and Concussion $\quad 13$

Sleep with History of Concussion 13

Sleep with History of Multiple Concussions 15

Assessment of Sleep Quality, Anxiety, and Depression 15

Depression and Anxiety Assessments 15

$\begin{array}{ll}\text { Sleep Assessments } & 16\end{array}$

$\begin{array}{ll}\text { Summary } & 17\end{array}$

$\begin{array}{ll}\text { CHAPTER III: METHODOLOGY } & 19\end{array}$

$\begin{array}{ll}\text { Study Design } & 19\end{array}$ 
$\begin{array}{ll}\text { Participants } & 19\end{array}$

$\begin{array}{ll}\text { Instrumentation } & 22\end{array}$

Pittsburgh Sleep Quality Index (PSQI) 22

Insomnia Severity Index (ISI) 22

State-Trait Anxiety Inventory (STAI) 23

Beck Depression Inventory, Version 2 (BDI-II) 23

$\begin{array}{ll}\text { Demographics Form } & 24\end{array}$

$\begin{array}{ll}\text { Procedures } & 24\end{array}$

$\begin{array}{ll}\text { Statistical Analysis } & 25\end{array}$

$\begin{array}{ll}\text { CHAPTER IV: RESULTS } & 27\end{array}$

Models 1 and 2: Trait Anxiety and Depression Bivariate Correlations Between Factors 27

Model 1: Trait Anxiety Mediation Model 28

Model 2: Depression Mediation Model 29

$\begin{array}{ll}\text { CHAPTER V: DISCUSSION } & 31\end{array}$

Sleep, Concussion History, Trait Anxiety, and Depression 32

Concussion History, Trait Anxiety, and Depression 33

$\begin{array}{ll}\text { Limitations } & 34\end{array}$

$\begin{array}{ll}\text { Conclusion } & 35\end{array}$

$\begin{array}{ll}\text { REFERENCES } & 36\end{array}$

APPENDIX A: PITTSBURGH SLEEP QUALITY INDEX (PSQI) 51

APPENDIX B: INSOMNIA SEVERITY INDEX (ISI)

APPENDIX C: STATE-TRAIT ANXIETY INVENTORY (STAI) FOR ADULTS 55 


\section{TABLES}

Table

Page

1. Demographics for College-Aged Young Adults $(n=246)$

19

2. Bivariate Correlations Among Factors with Trait Anxiety and Depression 


\section{FIGURES}

Figure $\quad$ Page

1. Trait Anxiety Mediation Model 29

2. Depression Mediation Model 30 


\section{CHAPTER I: INTRODUCTION}

A concussion, or mild traumatic brain injury, is defined as a traumatically induced transient disturbance of brain function that involves a complex pathophysiological process. ${ }^{1}$ Concussion is classified based on acute injury characteristics at the less severe end of the brain injury spectrum. ${ }^{1,2}$ A general misconception of concussions is that an individual must lose consciousness to be seen as "concussed", while the majority of concussions do not involve loss of consciousness; they may present, however, with various symptoms such as dizziness, headaches, blurred vision, and concentration problems. ${ }^{3}$ There can be a diverse multitude of signs and symptoms associated with a concussion that may be delayed in onset or initially unrecognized. ${ }^{1}$ Some clinical symptoms are somatic (e.g. headaches and nausea), cognitive (e.g. confusion, decreased attention, slowed mental processing, or "fogginess"), or emotional (e.g. anxiety, irritability, trouble sleeping, or sadness). ${ }^{1,3,4}$ Although observed symptoms typically resolve within 7 to 14 days, ${ }^{2}$ approximately $10 \%$ of individuals experience prolonged symptoms ${ }^{5}$ and emerging research is exploring the varying effects of prolonged symptoms that may go unresolved such as chronic headaches and fatigue, memory impairment, mood disturbances (i.e. anxiety and depression) requiring psychological interventions, and sleep disturbances. ${ }^{5-7}$

The two most frequent and underreported long-term sequelae of concussions are mood and sleep disturbances. ${ }^{8}$ Despite the high prevalence of these symptoms, few clinicians include psychosocial factors, emotional changes, and sleep disturbances in their concussion assessments. ${ }^{9}$ Anxiety and depression are present in up to $50 \%$ of athletes following acute concussion. ${ }^{10-12}$ Additionally, 50\% of concussed patients with psychiatric symptoms had a history of a preinjury psychiatric disorder. ${ }^{12}$ When these impairing disturbances within an individual's quality of life go undiagnosed or improperly managed, symptom severity may 
worsen, potentially leading to clinical depression, worsened ruminative thinking, clinical anxiety (i.e. generalized anxiety disorder), and even suicidal ideation and intent. ${ }^{12,13}$ Pre-injury risk factors, such as family mental health history, have been found to be predictive of ongoing impairment. ${ }^{14}$ Individuals that have an immediate family member with a history of a mental health disorder are predisposed to development of a mood disorder and should be carefully considered in evaluation and management of concussion. ${ }^{14}$ Additionally, poor sleep quality (i.e. trouble falling asleep, staying awake, and fatigue) and decreased sleep quantity (i.e. less amount of sleep) can have harmful effects on an individual's overall physical and mental health. ${ }^{15}$ Difficulty initiating or retaining sleep, recognized as insomnia, is a common affliction that can coincide with feelings of irritability or fatigue during wakefulness. ${ }^{16}$ Insomnia can produce physical pain such as headaches and abdominal pain, ${ }^{17}$ exacerbate conditions such as obesity, cardiovascular disease, and hypertension ${ }^{18}$, and negatively affect mental health by increasing mental distress, increasing feelings of hopelessness and sadness, and worsen ruminating thoughts. ${ }^{19}$ Insomnia has been found to be a risk factor for mental health conditions, such as depression, where the risk factor for depression among those with insomnia is strong. ${ }^{20}$

Although the presence of sleep and mood disturbances vary significantly among individuals following concussion, sleep and mood are collaborative in nature. Evidence shows that mood and sleep quality have a strong causal relationship and within that relation, mood has an effect on sleep and vice versa, with the effect of sleep quality on mood being significantly greater. ${ }^{21}$ It has been found that the relationship between mood and sleep quality is stronger in those who have concurrent anxiety and/or depression. ${ }^{21}$ Anxiety levels may affect how one perceives their sleep quality. ${ }^{22}$ Despite levels of anxiety, individuals may similarly experience equivalent sleep durations, but those with higher anxiety levels perceive their sleep quality as 
poor. ${ }^{22}$ With regards to concussion, patients who report moderate to severe emotional symptoms, such as sadness or feeling nervous or anxious, have a greater likelihood of reporting moderate to severe sleep disturbances later on throughout recovery. ${ }^{23}$ Sleep complaints subsequent to a concussion are a probable risk factor for later development of worsened feelings of depression and irritability. ${ }^{24}$ Difficulties falling asleep, drowsiness, and sleeping more than usual are common sleep disturbances in those with a history of concussion and have been linked to poorer mood disturbance scores. ${ }^{25}$ Post-concussion sleep disturbances have been shown to predict decrements in mental health, such as symptoms of depression, anxiety, and apathy 1 year postinjury. ${ }^{26}$ Despite these directional relationships, to our knowledge, there is no evidence that examines the effect of history of concussions on sleep and mood disturbances collectively.

It is essential for clinicians to recognize and understand mood and sleep disturbances in those with a history of concussion, as they both can become more prevalent and possibly more severe over time. ${ }^{27}$ Individuals with a greater historical number of concussions, or concussion history, are at greater risk for experiencing long-term problems in mood and cognition. ${ }^{27}$ Concussions create a cascade of molecular, hemodynamic, and electrophysiological alterations in the brain and is responsible for cognitive dysfunction and creation of vulnerability for repeated injury..$^{10}$ These effects are worsened and extended in the event of repeated concussions, as well as with multiple comorbidities or risk factors such as anxiety and depression. ${ }^{28} \mathrm{~A}$ lifetime accumulation of two or more concussions can result in increased depression ${ }^{27}$ and greater sleep disturbances than a history of a singular concussion. ${ }^{29}$ It has been found that those with 3 or more concussions with higher mood disturbances experience significantly worse sleep disturbances compared to those with higher mood disturbance and only one concussion. ${ }^{25}$ Examination of mood and sleep disturbances is a major element missing in the assessment of concussion and 
recovery, especially in individuals with a history of concussion. Mismanagement of these disturbances can worsen symptom burden, resulting in increased emotional complications as well as a potential need for formal psychological interventions.

The primary purpose of this study was to examine the significance of relationships between sleep quality and the prevalence of mood disturbances in healthy young adults with and without a history of concussions. Furthermore, we aimed to explore the relationship between sleep and mood disturbances in individuals with a history of concussion as well as individuals' perceived sleep quality, depression, and trait anxiety levels. We hypothesized that history of concussions may directly impact trait anxiety and depression, mediated by sleep quality. Our secondary prediction was that individuals with greater sleep disturbances may experience greater mood disturbances and poorer perception of sleep quality. 


\section{CHAPTER II: REVIEW OF LITERATURE}

Concussions are a growing public health concern. As many as 3.8 million concussions occur in the United States per year during competitive sports and recreational activities; however, as many as $50 \%$ of concussions may go unreported. ${ }^{2}$ The expanding incidence of concussions and emerging possible long-term health risks continue to raise concern to the general public. Additionally, there is an emergent need for management of sleep disturbances

(i.e. insomnia and troubles initiation and retaining sleep) and mood disturbances (i.e. anxiety and depression) following a concussion. These disturbances can persist and linger for several years after an injury with elevated depression levels reported as long as 6 years post-injury ${ }^{30}$. As a consequence of prolonged depression and anxiety post-injury, risk for suicide is elevated $\sim 10$ years after a concussion, even if the individual did not present with any mood disorders prior to injury. ${ }^{31}$ It can be suggested that mood and sleep have a relationship since nearly all mood disorders exhibit co-occurring sleep abnormalities, ${ }^{32}$ indicating that sleep disturbances influence mood by not only acting as a side effect, but contributing to and maintaining dysfunction. ${ }^{8}$

There is limited research on the relationship between mood and sleep disturbances, particularly with concussions, and there is a need for an understanding as mood and sleep disturbances can be frequent in those with a history of concussion. Understanding the relationship between these areas can help clinicians better recognize and manage these disturbances post-injury and prevent detrimental consequences, such as suicide.

\section{Brain Anatomy}

The amygdala, an almond-shaped gray matter structure located deep within the temporal lobe, is essential for many of the behavioral expressions of emotion and the prefrontal cortex is responsible for the cognitive aspects of emotional responses. ${ }^{33}$ Functional interactions between 
the amygdala and prefrontal cortex facilitate emotional influences on cognitive processes such as decision-making, as well as the cognitive regulation of emotion. ${ }^{33}$ The brain network, or circuit, that regulates aspects of emotional behavior in the pathophysiology of mood disorders, such as anxiety and major depressive disorder, is the limbic-cortical-striatal-pallidal-thalamic circuits (LCSPT), which is formed by connections between the orbital and medial prefrontal cortex (OMPFC), amygdala, and hippocampal subiculum. ${ }^{34}$ Depression can be dispersed across various areas of the brain, though localized abnormalities can be identified. ${ }^{35}$ Areas in the cerebrum involved in depression include the dorsal and medial prefrontal cortex, the dorsal and ventral anterior cingulate cortex, the orbital frontal cortex, and the insula. ${ }^{35}$ The amygdala, hippocampus, medial prefrontal cortex, and bed nucleus of stria terminalis (BNST) are all involved in fear and anxiety responses, as well as stress responses. ${ }^{36}$

The brain structures involved most with sleep include the amygdala, hypothalamus, brain stem, and the pineal gland. ${ }^{37}$ The amygdala becomes increasingly active during REM (rapid eye movement) sleep. ${ }^{37}$ The hypothalamus, a peanut-sized structure located deep inside the cerebrum, contains clusters of nerve cells that act as control centers affecting sleep by shutting down the brain's arousal signals and initiating transition into sleep. ${ }^{38}$ The brain stem communicates with the hypothalamus to control the transitions between sleep and wake. ${ }^{37}$ Lastly, the pineal gland, located within the cerebrum's two hemispheres, and receives signals from the suprachiasmatic nucleus $(\mathrm{SCN}){ }^{37}$

\section{Anxiety}

Anxiety disorders, such as generalized anxiety disorder (GAD), are the most prevalent psychiatric problems among college-aged individuals. A large national epidemiologic survey with college-aged individuals found that $45.7 \%$ of college students had a diagnosed psychiatric 
disorder with approximately $11.9 \%$ of those disorders being an anxiety disorder. ${ }^{39}$ Individuals with generalized anxiety disorder (GAD) typically display excessive anxiety or worry more days than not, for at least 6 months, with ordinary day-to-day things such as personal health, work, social interactions, and everyday routine life circumstances that negatively affects their quality of life. ${ }^{40,41}$ GAD has been associated with higher odds for being absent to work and impairment of work performance and social functioning. ${ }^{42,43} \mathrm{GAD}$ makes a person's constant anxiety and worry difficult to control during their routine life circumstances. ${ }^{41}$ These hard-to-control feelings of anxiety include tension, feeling “on edge", difficulty concentrating, muscle tensions, and even physical symptoms of autonomic arousal (i.e. hyperventilation and tachycardia). ${ }^{41}$ Anxiety is one of the most common mental and emotional stress producers that is often described as a vague fear, a sense of apprehension, and restlessness. ${ }^{3}$ Various physiological responses can be associated with anxiety, including sweating, increased heart rate, increased blood pressure, stomach discomfort, chills, difficulty concentrating, irritability, and sleep disturbances. ${ }^{3}$ There are two factors of anxiety: state and trait anxiety. State anxiety reflects how a person feels in the current moment about various situations that may influence anxiety levels and trait anxiety describes how a person feels in general toward various situations that may influence anxiety levels. ${ }^{44}$

Young adulthood is a time of major life transitions as well as a period of risk for the development of anxiety. ${ }^{45} \mathrm{GAD}$ is a heritable disorder with a moderate genetic risk of approximately $30 \% .{ }^{46}$ Anxiety has been shown to develop through complex risk processes involving genetic influences, with suggestion that one's chance increases in developing anxiety or GAD if history of anxiety is present in their immediate family. ${ }^{46-48}$ 


\section{Depression}

Depression is a mood disorder where helplessness, misery, loss of energy, excessive guilt, diminished ability to think, changes in eating and sleeping habits, and recurrent thoughts of harming oneself, suicide, or death may be experienced. ${ }^{3}$ American university students $(\mathrm{n}=$ $1,455)$ were surveyed on depression, and $53 \%$ reported increasing depressive symptoms since beginning college. ${ }^{49}$ Approximately $7 \%$ of college students have reported having an incidence of major depressive disorder within their first year of college. ${ }^{50}$ Major depression, or major depressive disorder, is a serious disorder of immense clinical relevance. ${ }^{51}$ Diagnosis of major depressive disorder requires a distinct change of mood, characterized by sadness or irritability and supplemented by at least several psychophysiological deviations, such as disturbances in sleep, appetite, or sexual desire, loss of the ability to experience pleasure in work or with friends, crying, suicidal thoughts, and slowing of speech and action. ${ }^{51}$ These deviations must last at least 2 weeks and must interfere with work and family relations to meet the diagnostic criteria for major depressive disorder. ${ }^{51}$

There are factors that may contribute to depression, such as physical activity ${ }^{52}$ and socioeconomic status (SES) ${ }^{53}$. In general, those who suffer with depression are less physically active. ${ }^{52,54,55}$ In a meta-analysis on SES and depression, most of the studies found that individuals from lower SES groups had a higher chance of being depressed than higher SES groups and found that lower SES individuals are much for likely to persist in depression once depressed. ${ }^{53}$ Our study observed SES through two questions: total combined family income for the past 12 months and on average how much money per month do they receive assistance from friends or family. 
Suicide, a significant problem among college students, has often been associated with depression and is the third leading cause of death in young adults. ${ }^{56,57}$ Suicide is not a specific diagnosis but is a major risk factor associated with depression. A large survey on young adults reported that among 8,155 students, $6.7 \%$ reported suicidal ideation, $1.6 \%$ reported having a suicide plan, and $0.5 \%$ reported making a suicide attempt in the past year. ${ }^{58}$

\section{Mood, Anxiety, Depression and Concussion}

Mood, Anxiety, and Depression with History of Concussion

Neuroimaging studies have suggested that concussions are correlated with changes in amygdala structures. ${ }^{59,60}$ A previous study that observed the relationship between amygdala shape and mood state in collegiate football players found that amygdala shape was positively correlated with depression and total mood disturbance, suggesting that the amygdala structure is associated with negative mood and concussions. ${ }^{61}$ Additionally, there is evidence of alterations in limbic-frontal circuitry after concussion that mimics alterations that are found in major depression. ${ }^{62}$ More neurochemical alterations that have been found to be consistent between mood disorders and concussion is the occurrence of serotonin disturbance and decreased dopamine in the prefrontal cortex and brainstem. ${ }^{14}$

Individuals who have experienced a concussion can have acute behavioral and affective symptoms such as mood and personality changes, agitation, and feeling "more emotional". These symptoms can affect individuals with their day-to-day quality of life, most notably the social aspect of life ${ }^{63}$ College students have reported moderate to severe changes in their extracurricular activities and relationships with their peers following concussion, with isolation and cautiousness as the most common complaints. ${ }^{63}$ A significant proportion of concussed 
individuals were identified as experiencing moderate to severe changes such as, negative mood, increased irritability, loss of attention, and poorer memory, as well as social isolation. ${ }^{63}$

Recent consensus guidelines on concussion have grouped symptoms into six clinical profiles with the aim to better understand the heterogeneity of concussion: anxiety/mood, posttraumatic migraine, oculomotor, vestibular, cervical, and cognitive fatigue. ${ }^{14}$ Evidence supports that those with chronic post-concussion symptoms (i.e. 3 months post-injury) are often associated with the anxiety/mood clinical profile, where their mental health becomes the primary concern after injury. ${ }^{14}$ This particular profile is distinguished by emotional disturbances, such as anxiety, depression, hypervigilance of somatic complaints, and sleep dysregulation. ${ }^{14}$ Pre-injury risk factors such as mental health history, immediate family mental health history ${ }^{48}$, and biological sex can predispose the presence of the anxiety/mood clinical profile and overall prolonged emotional sequelae following a concussion. ${ }^{14}$ Another rationale for the presence of anxiety/mood profile and general emotional disturbances following a concussion is the overlap between concussion symptoms and those symptoms associated with mood and anxiety mental health conditions. ${ }^{14}$ For example, post-concussion syndrome and major depressive disorder have been found to have similar symptomology and the feeling of dizziness and imbalance associated with a concussion is qualitatively comparable to feelings of dizziness, lightheadedness, and unsteadiness included in the symptomology for panic/anxiety attacks. ${ }^{14}$ This commonality between symptoms may explain why individuals are reporting more emotional complications after concussion. ${ }^{14}$ In regards with state versus trait anxiety, individuals with extensive concussion history tend to experience more state anxiety than trait. ${ }^{64}$

A long-term follow-up study assessed patients 30 years after their traumatic brain injury, including concussions, to determine the occurrence of psychiatric disorders over time. ${ }^{65}$ The 
most common mental health disorder found was major depression, where $26.7 \%$ experienced it after injury, at the lifetime rate. ${ }^{65}$ Major depression was observed not only at the early stage following the injury, but throughout the 30 -year follow-up. ${ }^{65}$ The indication that concussions lead to depression may be due to the morphological changes of the brain's mood centers involving the hippocampus, amygdala, and prefrontal brain regions, that have been found in individuals with clinical depression. ${ }^{13}$ Although it is not unusual for athletes to exhibit emotional changes after a concussion, several factors may contribute to worsened and prolonged anxiety and mood disturbance symptoms. ${ }^{66}$ Neurochemical changes, such as serotonin disturbance and decreased dopamine in the prefrontal cortex and brainstem, are consistent between mood disorders and concussion. ${ }^{14}$ Additionally, organic brain changes may explain why mood and anxiety symptoms are observed post-injury. ${ }^{14}$ Mood, Anxiety, and Depression with History of Multiple Concussions

Exposure to multiple concussions has been associated with long-term problems in mood. ${ }^{27}$ A lifetime accumulation of two or more concussions as compared to a history of no reported concussions can result in worsening symptoms of changes to cognitive function and increased executive dysfunction and depression. ${ }^{27}$ When an individual has a history of multiple concussions, evidence shows risk factors and symptoms can increase significantly. A survey study completed by 2,552 retired professional football players found that the individuals with at least 2 concussions had 1.5 times the risk for lifetime depression, while those with 3 or more had 3 times greater risk. ${ }^{67}$

Those who have suffered multiple concussions have a risk for post-concussion syndrome/symptoms. ${ }^{1}$ Post-concussion syndrome may continue for weeks to months after the incident occurs, with commonly reported symptoms including headaches, insomnia, fatigue, 
noise or light sensitivity, cognitive problems such as memory loss, poor concentration, and problem-solving, and finally, psychological symptoms such as depressed mood, irritability, and anxiety. ${ }^{1}$ Individuals with a history of 3 or more concussions have significantly greater postconcussive symptom scores compared with those with a history of zero, one, or two concussions. ${ }^{68}$ Additionally, individuals with a history of multiple concussions may report more post-concussion symptoms in the first 3 months following their subsequent injury and report greater difficulties with depression, traumatic stress, anger, and cognitive functioning. ${ }^{68}$

Several studies have reported that NFL and college football athletes with a history of concussions are more likely to experience moderate to severe clinical depression. ${ }^{67,69}$ A survey study completed by 797 former Division I collegiate athletes, found an association between previous concussions and greater risk of severe depression and higher levels of impulsivity and aggression. ${ }^{69}$

\section{Sleep Quality}

Sleep is defined as, "a recurring, reversible neuro-behavioral state of relative perceptual disengagement from and unresponsiveness to the environment." Sleep is typically accompanied (in humans) by postural recumbence, behavioral quiescence, and closed eyes. ${ }^{70}$ The importance of sleep is becoming progressively recognized in maintaining health and wellbeing. There are many functions of sleep, including promoting growth, learning, cognitive development, ${ }^{71}$ and even has a role in immunity. ${ }^{72}$

Sleep is critical for normal daily function. When deficiencies are present in both sleep quality and quantity, due to sleep-wake disturbances, it can cause impairments in one's cognitive, psychological, and physical function. ${ }^{73}$ Sleep loss and sleep disorders are among the most common, yet frequently overlooked health problems. It is estimated that 50 to 70 million 
Americans suffer chronically from a sleep disorder and restlessness, hindering quality of life, daily functioning, and negatively affecting health. ${ }^{19}$ The most reported sleep problem, insomnia, is a highly prevalent disorder and despite its adverse effect on health and quality of life, it often goes unrecognized and untreated. ${ }^{19}$ Insomnia is defined "by having difficulty falling asleep, maintaining sleep, or by short sleep duration, despite adequate opportunity for a full night's sleep". ${ }^{19}$ Additional insomnia symptoms can involve daytime consequences, specifically tiredness, lack of energy, difficulty concentrating, or irritability. ${ }^{19}$ Young adults with insomnia symptoms can demonstrate significantly higher rates of psychiatric symptoms compared to those without insomnia. ${ }^{74}$ College students with sleep disturbance and depressive symptoms may demonstrate significantly more intense and frequent anxiety and poor cognitive and physical functioning. ${ }^{74}$

Sleep has been referred to as a "pillar of mental health", signifying how every major psychiatric disorder is associated with a high prevalence of sleep disturbances.$^{75}$ Mood is casually impacted by sleep disturbances, meaning that an individual's sleep alterations are not simply a side effect of the disorder but rather actively contribute to and maintain dysfunction. ${ }^{8}$ Adverse effects on mood and behavior have been connected with sleep loss. ${ }^{19}$ Adults with chronic sleep loss report increased mental distress, depressive symptoms, and anxiety. ${ }^{19,76}$

\section{Sleep and Concussion}

Sleep with History of Concussion

Previous evidence supports that it is common to experience sleep alterations and poorer self-reported sleep quality both immediately and several years following concussion. ${ }^{8}$ Specifically, those who have a history of a concussion report poorer sleep quality and daytime sleepiness relative to healthy controls. ${ }^{8,15}$ Although various conditions or special circumstances 
can cause sleep disturbances, sleep-wake disturbances have been commonly reported following concussions. ${ }^{77}$ It is estimated that $30 \%-80 \%$ of diagnosed concussed individuals will experience sleep-wake disturbances such as insomnia, increased time falling asleep, difficulty remaining asleep, and increased fatigue or feelings of tiredness throughout the day. ${ }^{29,73,78,79}$ Sleep disturbances can be indications of disruption during sleep or indicators of the presence of clinical sleep disorders. ${ }^{29}$ It is essential that concussed individuals obtain adequate sleep during the recovery process to decrease symptom burden and restore the electrochemical balance or the recovery phase may be prolonged. ${ }^{29,80}$

When concussed individuals experience sleep-wake disturbances along with their other emotional, somatic, and cognitive-type symptoms, the discrepancies in their sleep quality and quantity could significantly aggravate their symptoms and prolong or delay their recovery. ${ }^{73}$ When sleep quality is affected due to concussion, it may alter one's quality of life. ${ }^{29}$ Changes in sleep quality and quantity after a concussion have been related to decreased quality of life including diminished engagement in physical activity or sport, academic performance, and social or leisure activities. ${ }^{29}$

Sleep patterns with concussions can be correlated with mood disturbances such as anxiety and depression. ${ }^{81}$ A study that observed sleep patterns following concussion found that patients with a concussion had significantly shorter sleep duration and sleep quality, but interestingly, they also found that sleep disturbances following concussion can be associated with anxiety and depression. ${ }^{81}$ It is suggested that some features of anxiety, such as increased arousal at night, can lead to sleep disruption and then resulting in changes in sleep duration and subjective sleep quality. ${ }^{81}$ 
Sleep with History of Multiple Concussions

The indication that repeated concussions may have adverse effects on sleep quality has been gradually escalating. ${ }^{25}$ Some of the literature suggests that sleep disturbance after repeated concussions may have more harmful effects than a history of a single concussion. ${ }^{25} \mathrm{~A}$ study, where it's purpose was to determine if concussion history was related to ongoing sleep disturbances, found that the greater number of concussions, the greater sleep disturbances they experienced, with the most commonly reported sleep disturbances being fatigue, restlessness, sleeping too little, and difficulty falling and staying asleep. ${ }^{29}$ History of repeated concussions may be associated with more drowsiness at higher severity and subsequently, a worsening of post-concussive symptoms. ${ }^{25}$

\section{Assessment of Sleep Quality, Anxiety, and Depression}

Depression and Anxiety Assessments

The Beck Depression Inventory Version II (BDI-II) is a 21-item self-reporting questionnaire designed to evaluate the level of depressive symptoms present over the two weeks' period in normal and psychiatric populations. ${ }^{82}$ The BDI-II utilizes a 4-point scale from 0 (no symptoms) to 3 (more severe symptoms) that assess affective, cognitive, somatic and vegetative symptoms, reflecting criteria for major depression. ${ }^{82}$ Scoring is achieved by calculating the sum of the 21 items, where the minimum score is 0 and maximum score is 63 , with higher scores signifying greater symptom severity. ${ }^{82}$ This assessment uses a cut off score of 20 to indicate depression. ${ }^{82}$ The BDI-II has shown to have high internal consistency reliability with a Cronbach's $\alpha$ of 0.92 for an outpatient population and .93 for college student population. ${ }^{83}$

The State-Trait Anxiety Inventory (STAI) is a self-reported anxiety assessment that consists of 40 statements, with 20 measuring state anxiety (i.e. the current state of anxiety, how 
respondents feel "right now," feelings of apprehension, tension, nervousness, and worry) and the other 20 measuring trait anxiety (i.e. relatively stable aspects of “anxiety proneness," general states of calmness, confidence, and security). ${ }^{84}$ This assessment measures the prevalence and severity of current anxiety symptoms and a generalized susceptibility of anxiousness. ${ }^{84}$ For state anxiety, responses range from 1 to 4 with 1 indicating "not at all" to 4 indicating "very much so". ${ }^{84}$ For trait anxiety, responses range from 1 to 4 with 1 indicating "almost never" to 4 indicating "almost always". ${ }^{84}$ The STAI does not utilize a specific cut-off score, instead respondents are identified as "more anxious than the norm" or "less anxious than the norm". It has been shown that the STAI's internal consistency alpha coefficients are quite high ranging from 0.86 to $0.95 .^{85}$

Sleep Assessments

Various sleep quality assessments have been used along with concussions, including Pittsburgh Sleep Quality Index (PSQI), Epworth Sleepiness Scale (ESS), Insomnia Severity Index (ISI), Actigraphy, Polysomnography (PSG), and sleep diaries. ${ }^{86,87}$ The two sleep assessment questionnaires that have shown consistent reliability and validity are the PSQI and ISI. ${ }^{86}$ The PSQI is an 19-item, self-reported questionnaire that assesses a variety of sleep-related behaviors. ${ }^{86}$ It provides an overall global score and seven component scores that assess eight domains: subjective sleep quality, sleep latency, sleep duration, sleep efficiency, sleep disturbances, use of sleep medication, and daytime dysfunction. ${ }^{86}$ The global score ranges from 0 to 21 , with a higher score indicating poorer sleep quality. ${ }^{86}$ The PSQI has been shown consistently to be a valid and reliable $(\alpha=0.83)$ measure of sleep-related disturbances. ${ }^{86}$ The PSQI has a sensitivity of $89.6 \%$ and specificity of $86.5 \%$ for identifying cases with sleep disorder, utilizing a cut-off score of $5{ }^{88}$ A study that tested the validity of the PSQI found that 
the questionnaire's global score demonstrated excellent internal consistency (Cronbach's alpha $.72)$ and found that the global score showed moderate and significant correlations with mood $(\mathrm{r}=$ $-0.35 ; \mathrm{p} \leq 0.001)$ and fatigue $(\mathrm{r}=0.42 ; \mathrm{p} \leq 0.001){ }^{89}$

The ISI is another self-reported sleep questionnaire with 7 items that aim to evaluate sleep difficulties associated with insomnia. ${ }^{86}$ The ISI assesses the severity of an individual's onset of sleep and difficulties of sleep maintenance, satisfaction with their current sleep pattern, interference with daily functioning, noticeability of impairment due to their sleep problem, and distress that is affected by the sleep problem. ${ }^{90}$ It takes less than five minutes to complete the seven items on the ISI. ${ }^{90}$ Items on the questionnaire are rated on a 0-4 Likert scale and total score ranges from 0 to 28 , with a higher score representing greater insomnia severity. ${ }^{90}$ A cut-off score of $<15$ is used to determine patients who do not meet the diagnostic requirements for insomnia. ${ }^{90}$ The ISI demonstrates significant reliability and validity and is an adequate method to quantify perceived insomnia severity. ${ }^{90}$ Internal consistency of the ISI $=0.074$ and all correlation coefficients were significant at the $\mathrm{p} \leq 0.001$ level. ${ }^{90}$

\section{Summary}

A growing body of evidence shows that a history of concussions can lead to the risk of prolonged depression and anxiety symptoms, ${ }^{63,65,91,92}$ but more research is needed to further examine the directional impact of these factors. Despite the evidence associating concussion history and emotional disturbances, the direct relationship between disturbances remains largely unexplored and poorly understood. There is an emergent need for a better understanding of mood-related behaviors pertaining to concussions and there are limited guidelines for treating emotional influences post-concussion. Due to the potential overlapping relationship of moodrelated symptoms and sleep quality, assessment of sleep and mood disturbances in patients 
following a concussion is paramount. Identifying the prevalence of mood disorder symptoms, such as depression and anxiety, and sleep quality in those with a history of concussion, especially multiple concussions, could prevent prolonged mental health symptoms that can lead to detrimental consequences, such as suicide. The purpose of this study was to determine the relationship of sleep quality and the prevalence of anxiety and depression in healthy young adults with and without a history of concussion. 


\section{CHAPTER III: METHODOLOGY}

\section{Study Design}

This study was an anonymous observational cross-sectional survey that assessed the directional impact of sleep quality and mood disturbances on individuals with and without a history of concussion, with participants completing sleep and mood disturbance questionnaires at one time-point.

\section{Participants}

A total of 436 young adults between the ages of 18 to 35 years were observed from 3 universities: 1 large-sized Midwest, 1 medium-sized Midwest, and 1 medium-sized Mid-Atlantic institution. Participants were included if they self-reported a past medical history of concussion or if they had no history of a concussion (i.e., never been diagnosed with a concussion by a healthcare professional or did not believe they had suffered a head injury) and if they could read and understand English. Exclusion criteria were determined via self-reported demographic forms and included individuals who suffered a concussion or traumatic brain injury within the past 6 months, history of cancerous brain tumors, diagnosed with post-traumatic stress disorder, schizophrenia, or bipolar disorder. Based on exclusion criteria, 47 participants were removed from the analysis. Out of 389 participants, 143 did not finish the survey in its entirety (including demographics), with a final sample of 246 young adults (Table 1) and a survey completion rate of $63.2 \%$. This study was approved by the University's Institutional Review Board and informed consent was obtained from each participant prior to proceeding with surveys.

Table 1. Demographics for College-Aged Young Adults $(n=246)$

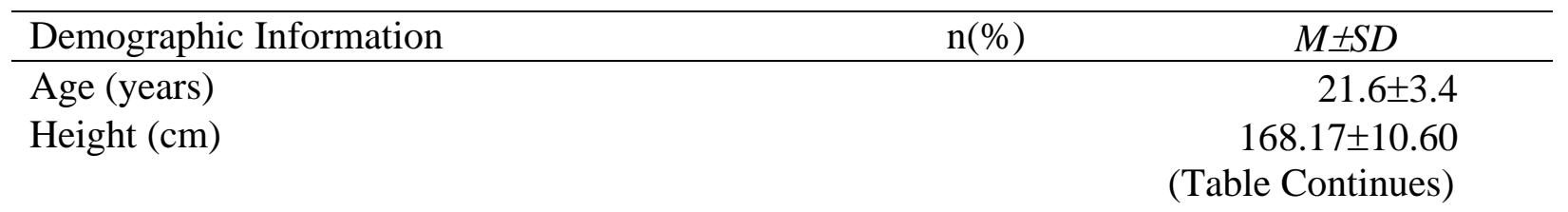




\begin{tabular}{|c|c|c|}
\hline $\begin{array}{l}\text { Weight }(\mathrm{kg}) \\
\text { BMI }\left(\mathrm{kg} / \mathrm{m}^{2}\right)\end{array}$ & & $\begin{array}{r}72.47 \pm 17.46 \\
25.65 \pm 5.81 \\
\end{array}$ \\
\hline \multicolumn{3}{|l|}{ Gender } \\
\hline Female & $183(74.4)$ & \\
\hline Male & $54(22.0)$ & \\
\hline Nonbinary & $7(2.8)$ & \\
\hline Other (AFAB Genderfluid) & $1(0.4)$ & \\
\hline Prefer not to answer & $1(0.4)$ & \\
\hline \multicolumn{3}{|l|}{ Race (physical traits) } \\
\hline Asian & $4(1.6)$ & \\
\hline Black/African & $8(3.3)$ & \\
\hline White Caucasian & $201(81.7)$ & \\
\hline Hispanic/Latinx & $8(3.3)$ & \\
\hline Other & $19(8.1)$ & \\
\hline \multicolumn{3}{|l|}{ Ethnicity (cultural identification) } \\
\hline Asian & $5(2.0)$ & \\
\hline Black/African & $8(3.3)$ & \\
\hline White Caucasian & $211(85.8)$ & \\
\hline Hispanic/Latinx & $15(6.1)$ & \\
\hline Prefer not to answer & $2(.8)$ & \\
\hline Other & $5(2.0)$ & \\
\hline \multicolumn{3}{|l|}{ Physical Activity Level } \\
\hline High & $45(18.3)$ & \\
\hline Moderate & $88(35.8)$ & \\
\hline Low & $111(45.1)$ & \\
\hline \multicolumn{3}{|l|}{ Highest Degree or Education Completed } \\
\hline Bachelor's degree & $52(21.1)$ & \\
\hline High school graduate or GED completion & $29(11.8)$ & \\
\hline Master's degree & $13(5.3)$ & \\
\hline PhD or higher & $3(1.2)$ & \\
\hline Some college & $143(58.1)$ & \\
\hline Some high school & $1(.4)$ & \\
\hline Trade school & $2(.8)$ & \\
\hline \multicolumn{3}{|l|}{ University or College } \\
\hline Large-sized Midwest Institution & $228(92.7)$ & \\
\hline Medium-sized Mid-Atlantic Institution & $7(2.8)$ & \\
\hline Medium-sized Midwest Institution & $5(2.0)$ & \\
\hline \multicolumn{3}{|l|}{ Institution Type } \\
\hline Two-year & $6(2.4)$ & \\
\hline Four-year & $235(95.5)$ & \\
\hline
\end{tabular}




\begin{tabular}{|c|c|}
\hline \multicolumn{2}{|c|}{ Father's Highest Degree or Education Completed } \\
\hline Bachelor's degree & $68(276)$ \\
\hline High school graduate or GED completion & $47(19.1)$ \\
\hline Master's degree & $36(14.6)$ \\
\hline $\mathrm{PhD}$ or higher & $11(4.5)$ \\
\hline Some college & $47(19.1)$ \\
\hline Some high school & $13(5.3)$ \\
\hline Trade school & $13(5.3)$ \\
\hline Unknown & $8(3.3)$ \\
\hline \multicolumn{2}{|l|}{ Mother's Highest Degree or Education } \\
\hline Completed & $96(39.0)$ \\
\hline Bachelor's degree & $33(13.4)$ \\
\hline High school graduate or GED completion & $52(21.1)$ \\
\hline Master's degree & $1(0.4)$ \\
\hline $\mathrm{PhD}$ or higher & $58(23.6)$ \\
\hline Some college & $1(0.4)$ \\
\hline Some high school & $4(1.6)$ \\
\hline Trade school & $1(0.4)$ \\
\hline Unknown & \\
\hline \multicolumn{2}{|l|}{ Total Combined Family Income } \\
\hline 150,000 , or more & 26(10.6) \\
\hline 100,000 through 149,000 & $57(23.2)$ \\
\hline 75,000 through 99,999 & $42(17.1)$ \\
\hline 50,000 through 74,999 & $30(12.2)$ \\
\hline 35,000 through 49,999 & 28(11.4) \\
\hline 25,000 through 34,999 & $14(5.7)$ \\
\hline 15,000 through 24,999 & $13(5.3)$ \\
\hline 5,000 through 14,999 & $21(8.5)$ \\
\hline Less than 5,000 & $8(3.3)$ \\
\hline \multicolumn{2}{|l|}{ Monthly Financial Assistance } \\
\hline$\$ 500$ or more & $21(8.5)$ \\
\hline$\$ 400.00$ through $\$ 499.99$ & $6(2.4)$ \\
\hline$\$ 300.00$ through $\$ 399.99$ & $4(1.6)$ \\
\hline$\$ 200.00$ through $\$ 299.99$ & $6(2.4)$ \\
\hline$\$ 100.00$ through $\$ 199.99$ & $27(11.0)$ \\
\hline$\$ 50.00$ through $\$ 99.99$ & $35(14.2)$ \\
\hline$\$ 25.00$ through $\$ 49.99$ & $33(13.4)$ \\
\hline Less than $\$ 25.00$ & $27(11.0)$ \\
\hline None & $85(34.6)$ \\
\hline
\end{tabular}

Note: $\mathrm{N}=246$. $\mathrm{BMI}=$ body mass index, $\mathrm{AFAB}=$ assigned female at birth. Missing data from race $(\mathrm{n}=5)$, highest degree or education completed $(\mathrm{n}=3)$, father's highest degree or education completed $(n=3)$, total combined family income $(n=7)$, monthly financial assistance $(n=2)$, and physical activity level $(\mathrm{n}=2)$. 


\section{Instrumentation}

Self-reported questionnaires used in this study included the Pittsburgh Sleep Quality Index (PSQI), Insomnia Severity Index (ISI), State Trait Anxiety Inventory (STAI), and the Beck Depression Inventory, Version 2 (BDI-II). These questionnaires were distributed using a Qualtrics web-based survey platform (Qualtrics, Provo, UT, USA) across multiple institutions. Pittsburgh Sleep Quality Index (PSQI)

The PSQI is a19-item, self-reported questionnaire that assesses a variety of sleep-related behaviors from the past month and takes 5-10 minutes to complete. ${ }^{86,93}$ It provides an overall global score and component sub scores within seven domains: subjective sleep quality, sleep latency, sleep duration, sleep efficiency, sleep disturbances, use of sleep medication, and daytime dysfunction. ${ }^{86}$ The PSQI's global score ranges from 0 to 21 , with a higher score indicating poorer sleep quality, and utilizes a more sensitive cut-off score of $>8$ to identify those with insomnia in this population. ${ }^{78,86,88}$ The PSQI has been shown to be a valid and reliable $(\alpha=0.83)$ measure of sleep-related disturbances with a sensitivity of $89.6 \%$ and specificity of $86.5 \%$ for identifying cases with sleep disorders. ${ }^{86,88}$

Insomnia Severity Index (ISI)

The ISI is a self-reported sleep questionnaire with 7 items that aim to evaluate sleep difficulties associated with insomnia and takes less than 5 minutes to complete. ${ }^{86,90}$ The ISI assesses the severity of sleep-onset and sleep maintenance complications, satisfaction with current sleep patterns, how sleep interferes with daily functioning, noticeability of impairment from sleep problems, and degree of distress caused by the sleep problem. ${ }^{90}$ Items on the questionnaire are rated on a 0-4 scale and the total score ranges from 0 to 28 , with a higher score representing greater insomnia severity. ${ }^{90} \mathrm{~A}$ cut-off score of $<15$ is used to determine patients 
who do not meet the diagnostic requirements for insomnia. ${ }^{90}$ The ISI has been shown to have an acceptable reliability and validity and is an adequate method to quantify perceived insomnia severity, with an internal consistency $(\alpha=0.74) .{ }^{90}$

\section{State-Trait Anxiety Inventory (STAI)}

The STAI is a self-reported anxiety assessment that consists of 40 statements, with 20 measuring state anxiety (i.e. the current state of anxiety, how respondents feel "right now," feelings of apprehension, tension, nervousness, and worry) and the other 20 measuring trait anxiety (i.e. relatively stable aspects of "anxiety proneness," general states of calmness, confidence, and security). ${ }^{84}$ The STAI measures the prevalence and severity of current anxiety symptoms and a generalized susceptibility of anxiousness. ${ }^{84}$ For trait anxiety, responses range from 1 to 4 with 1 indicating "almost never" to 4 indicating "almost always". ${ }^{84}$ Both state and trait anxiety scales have scores that range from 20 to 80 , with higher scores indicating a greater level of anxiety. We aimed to focus primarily on trait anxiety for this study since trait anxiety describes how a person feels in general, rather than just in the moment, toward various situations that may influence their anxiety. ${ }^{44}$ To observe the long-term effects of concussion history, observation of trait anxiety is more plausible to observe than state anxiety. To classify anxiety with the STAI, respondents are identified as "more anxious than the norm" or "less anxious than the norm". It has been shown that the STAI's internal consistency alpha coefficients are quite high ranging from 0.86 to $0.95 .^{85}$

\section{Beck Depression Inventory, Version 2 (BDI-II)}

The BDI-II is a 21-item self-reporting questionnaire designed to evaluate the level of

depressive symptoms present over the two weeks' period in normal and psychiatric populations. ${ }^{82}$ The BDI-II utilizes a 4-point scale from 0 (no symptoms) to 3 (more severe symptoms) that 
assess affective, cognitive, somatic and vegetative symptoms, reflecting criteria for major depression. ${ }^{82}$ Scoring is achieved by calculating the sum of the 21 items, where the minimum

score is 0 and maximum score is 63 , with higher scores signifying greater symptom severity. ${ }^{82}$ This assessment uses a cut-off score of 20 to indicate depression. ${ }^{82}$ The BDI-II has shown to have high internal consistency reliability with a Cronbach's $\alpha$ of 0.92 for an outpatient population and 0.93 for a college student population. ${ }^{83}$

\section{Demographics Form}

Participants were asked to self-report demographic information to ascertain age, gender, race, ethnicity (i.e. describes their feeling of belonging and attachment to a distinct group of a larger population that shares their ancestry, language, or religion), level of education, institution setting, socioeconomic status (i.e. parental education level, combined family income, and personal monthly financial assistance), physical activity level, current medications (i.e. antipsychotics), concussion history, medical history (i.e. diagnosed with depression or anxiety disorder), and immediate family mental health history. Physical activity was determined using the International Physical Activity Questionnaire- Short Form (IPAQ-SF) ${ }^{94}$ Concussion history questions examined number of diagnosed and undiagnosed concussions, when they occurred, and the mechanism of injury (i.e. motor vehicle accident, sport-related concussion, etc.).

\section{Procedures}

Participants were recruited through convenience sampling at the two local universities and word-of-mouth by remote investigators at the Mid-Atlantic institution. All institutions provided participants with instructions on the purpose of the study and details on the survey. Surveys were distributed via an anonymous Qualtrics link and took approximately 15-20 minutes to complete. At the start of the survey, participants were asked if they suffered a concussion or 
traumatic brain injury within the past 6 months, had a history of cancerous brain tumors, had been diagnosed with post-traumatic stress disorder, schizophrenia, or bipolar disorder. If they said yes to any of the exclusion criteria, the survey ended. Participants who met the criteria proceeded with four questionnaires: PSQI, ISI, STAI, BDI-II, and a demographics form. Informed consent was delivered at the beginning of the survey and within the consent the participants were made aware that, if needed, they could withdraw from the survey at any point.

Medical history exclusion criteria were verified first, then the PSQI was performed followed by the ISI, STAI, BDI-II, and finished with final demographic questions. This order was carefully decided with imperative medical history gathered initially, then questionnaires were placed in this order by projected completion duration and finishing with additional demographic information that involved less cognitive effort to control for survey fatigue. Survey fatigue, also known as respondent fatigue, is a common issue in survey research and factors that are known to influence this are length of survey, question complexity, and too many open-ended questions. ${ }^{95}$ Knowing this, in our survey we made sure to not include too many open-ended questions and for the questions to be clear and concise.

\section{Statistical Analysis}

Structural equation models were performed in Mplus 8.0 (Muthen \& Muthen, User's Guide, Eighth Edition. Los Angeles, CA). Before conducting the mediation analysis, data were inspected for normality. Concussion history and gender were not normally distributed, therefore were transformed using a log base ten transformation. Path analyses were conducted to test the hypothesis of concussion history directly impacting anxiety and depression and determined if sleep quality mediated this relationship. Two separate mediation models for trait anxiety and depression were performed. We observed for an amount of variance $\left(\mathrm{R}^{2}\right)$ and standard error (SE) 
with concussion history on trait anxiety and depression. Full information robust maximum likelihood estimation is robust to data loss and can handle up to $25 \%$ missing data. Critical z scores (parameter estimate/standard error) were used to test the significance of relations (fully standardized $\beta$ coefficients) between variables $(p<.05)$. Based on previous research, we controlled for gender, BMI, socioeconomic status, family history of an anxiety disorder, and physical activity. Bivariate correlations were utilized for all model variables (Concussion history, gender, physical activity, age, BMI, STAI Y2 levels, and BDI-II levels) and were computed using IBM SPSS 25.0. 


\section{CHAPTER IV: RESULTS}

Approximately $74 \%$ of participants were females, $22.0 \%$ males, $2.8 \%$ non-binary, and $1 \%$ assigned female at birth (AFAB) genderfluid. With respect to concussion history, $64.6 \%$ of participants self-reported having no history of concussion, $26 \%$ had $1-2$ concussions, and $9.2 \%$ had $3+$ concussions. Out of those participants with diagnosed mood disorders, approximately $34 \%$ of participants stated that they have been diagnosed with a depression disorder and $38.2 \%$ stated they have been diagnosed with an anxiety disorder. Thirty-seven percent of participants reported having at least one immediate relative with a diagnosed depression disorder and $43.5 \%$ have at least one immediate relative with a diagnosed anxiety disorder.

\section{Models 1 and 2: Trait Anxiety and Depression Bivariate Correlations between Factors}

The Bivariate correlation coefficients of the study variables for models 1 and 2 are presented in Table 2. The correlations indicated a significant relationship between number of concussions and PSQI $(\mathrm{r}=0.22, \mathrm{p}<0.01)$. Poor sleep quality scores were significantly correlated with trait anxiety $(\mathrm{r}=0.60, \mathrm{p}<0.01)$ and depression $(\mathrm{r}=0.59, \mathrm{p}<0.01)$, where individuals who experienced poorer sleep quality had higher trait anxiety and worsened depression, respectively. Trait anxiety was also significantly correlated with age $(r=-0.20, p<0.01)$ and BMI $(r=0.13$, $\mathrm{p}=0.04$ ), where individuals who were younger and had greater BMI scores, expressed higher trait anxiety. Depression levels were significantly correlated with age $(r=-0.17, p<0.01)$, BMI $(r=0.18$, $\mathrm{p}=<0.01)$, and number of concussions $(\mathrm{r}=0.15, \mathrm{p}=0.02)$, where individuals who were younger,

had greater BMI scores, and greater number of concussions, experienced worsened depression. 
Table 2. Bivariate Correlations Among Factors with Trait Anxiety and Depression

\begin{tabular}{lcccccccc} 
Variable & $\begin{array}{c}\text { Concussion } \\
\text { History }\end{array}$ & Gender & PA & $\begin{array}{c}\text { Sleep } \\
\text { Quality }\end{array}$ & Age & BMI & $\begin{array}{r}\text { STAI } \\
\text { (trait) }\end{array}$ & BDI-II \\
\hline Concussion & -- & & & & & & & \\
History & & & & & & & & \\
Gender & 0.11 & --- & & & & & \\
PA & -0.08 & -0.06 & --- & & & & \\
Sleep Quality & $0.22^{* *}$ & -0.07 & -0.07 & --- & & & \\
Age & 0.02 & -0.02 & $0.14^{*}$ & -0.08 & --- & & \\
BMI & 0.08 & 0.02 & -0.004 & 0.07 & $0.14^{*}$ & --- & & \\
STAI (trait) & 0.10 & -0.12 & -0.01 & $0.60^{* *}$ & $-0.20^{* *}$ & $0.13^{*}$ & --- & \\
BDI-II & $0.15^{*}$ & -0.03 & 0.03 & $0.59^{* *}$ & $-0.17^{* *}$ & $0.18^{* *}$ & $0.85^{* *}$ & --- \\
\hline
\end{tabular}

Note. $\mathrm{PA}=$ physical activity, BMI=body mass index, STAI (trait)=trait anxiety, and BDI-II=Beck Depression Index, Version 2. $* p<0.05, * * p<0.01$ (2-tailed).

\section{Model 1: Trait Anxiety Mediation Model}

The hypothesized structural model (Figure 1) illustrates relationships between concussion history, sleep, and trait anxiety. The model accounted for a significant $(\mathrm{p}<0.05)$ amount of variance $\left(\mathrm{R}^{2}, \mathrm{SE}\right)$ for concussion history $\left(\mathrm{R}^{2}=7.9 \%, \mathrm{SE}=3.4 \%\right)$ and PSQI scores $\left(\mathrm{R}^{2}=37.3 \%\right.$, $\mathrm{SE}=5.0 \%$ ) on trait anxiety. Mediation analysis indicated no direct effects of concussion history on trait anxiety $(\beta=-0.001, p=0.480)$. The number of concussions had a significant effect on PSQI $(\beta=0.019, \mathrm{SE}=0.005, \mathrm{p}<0.001)$. The PSQI scores had a significant effect on trait anxiety $(\beta=0.168, \mathrm{SE}=0.015 \mathrm{p}<0.001) . \mathrm{BMI}$, gender, physical activity, and age covariates were nonsignificant $(\mathrm{p}>0.05)$. 


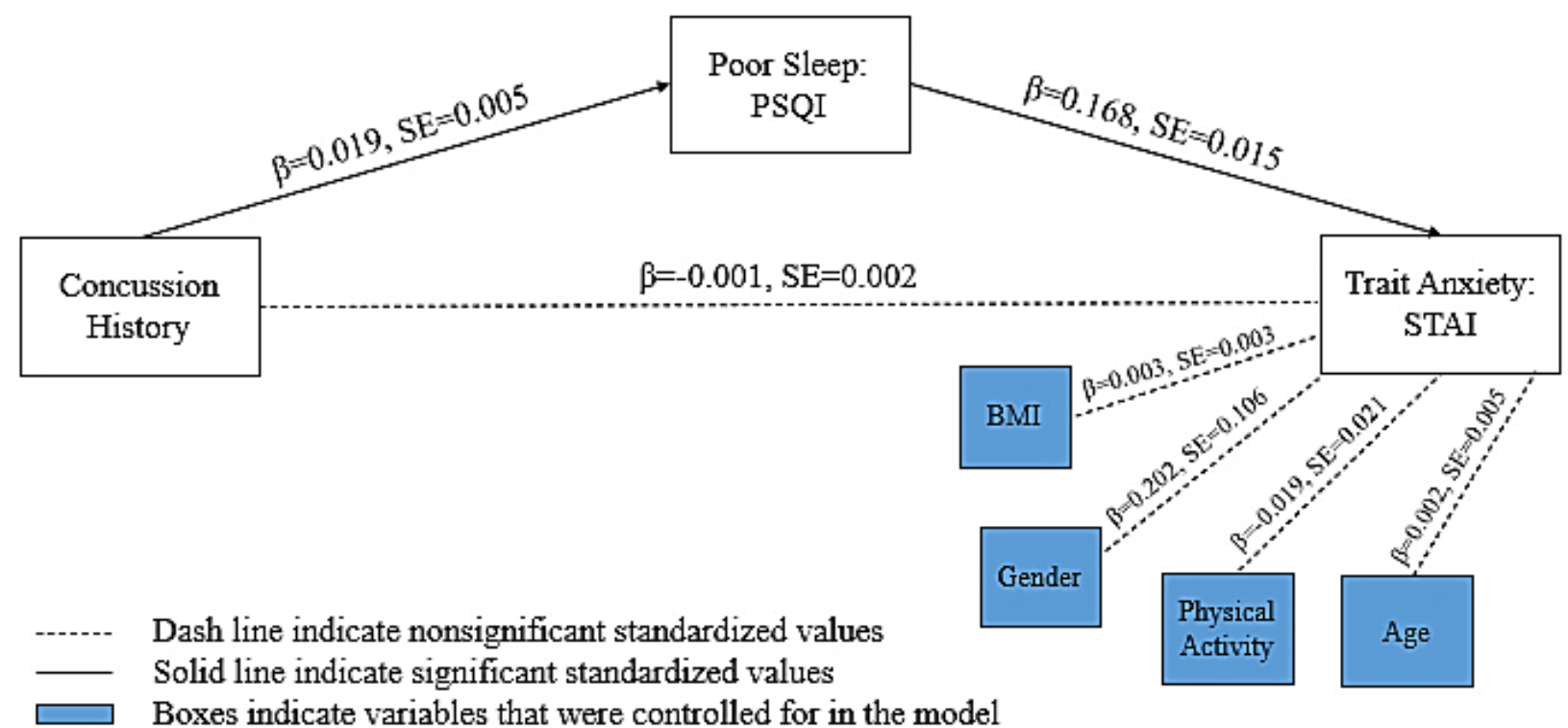

Figure 1. Trait Anxiety Mediation Model Structural model of hypothesized associations among number of concussions, trait anxiety, and sleep quality.

\section{Model 2: Depression Mediation Model}

The hypothesized structural model (Figure 2) illustrates relationships between concussion history, sleep, and depression. The model accounted for a significant $(\mathrm{p}<0.05)$ amount of variance $\left(\mathrm{R}^{2}, \mathrm{SE}\right)$ for concussion history $\left(\mathrm{R}^{2}=7.7 \%, \mathrm{SE}=3.3 \%\right)$ and PSQI scores $\left(\mathrm{R}^{2}=36.6 \%\right.$, $\mathrm{SE}=5.0 \%$ ) on depression. Mediation analysis indicated no direct effects of concussion history on depression $(\beta=0.001, p=0.695)$. The number of concussions had a significant effect on PSQI $(\beta=0.015, \mathrm{SE}=0.005, \mathrm{p}<0.001)$. The PSQI scores had a significant effect on depression $(\beta=0.186$, $\mathrm{SE}=0.016 \mathrm{p}<0.001)$. BMI, gender, physical activity, and age covariates were non-significant $(\mathrm{p}>0.05)$. 


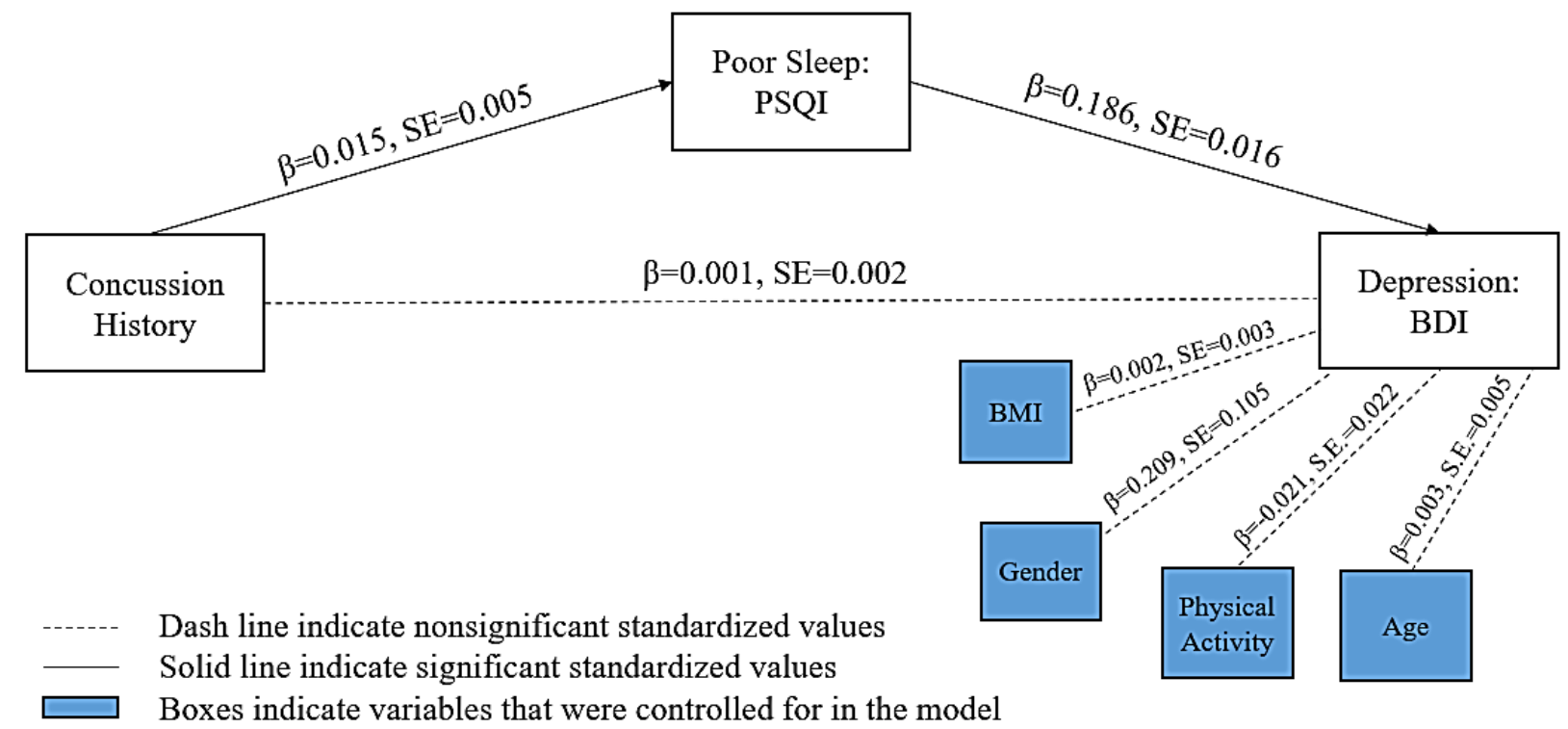

Figure 2. Depression Mediation Model Structural model of hypothesized associations among number of concussions, depression, and sleep quality. 


\section{CHAPTER V: DISCUSSION}

This study was the first, to our knowledge, to examine the directional relationship of trait anxiety and depression with concussion history and how that relationship was affected by sleep quality. Our findings suggest that concussion history may not influence trait anxiety and depression directly, but it may influence trait anxiety and depression through an indirect pathway of sleep quality. In our models, sleep quality explained $37.3 \%$ of variance within trait anxiety and $36.6 \%$ of variance with depression. Without consideration of sleep quality, only $7.9 \%$ and $7.8 \%$ of the variance in trait anxiety and depression, respectively, was explained. Therefore, to fully understand the variance in this model, it is important for clinicians to consider sleep quality. Sleep has been referred to as the "pillar of mental health",75, which makes it clear why sleep would directly affect anxiety and depression, aiding in the indirect relationship of concussion history and anxiety and depression. It can be suggested that mood and sleep have a relationship since nearly all mood disorders exhibit co-occurring sleep irregularities,${ }^{32}$ indicating that sleep disturbances influence anxiety and depression by not only acting as a side effect, but contributing to and maintaining dysfunction. ${ }^{8}$ Previous evidence has suggested that adults with chronic sleep loss commonly report increased mental distress, anxiety, and depressive symptoms, ${ }^{76}$ therefore, consideration of sleep quality may aid clinicians in understanding the influences on anxiety and depression.

Our bivariate correlations suggest that trait anxiety was associated with age and BMI, where younger individuals who had greater BMI scores, expressed higher trait anxiety. Additionally, depression levels were correlated with age, BMI, and concussion history, where younger individuals who had greater BMI scores and greater number of concussions, experienced worsened depression. Our findings are consistent with Bjerkeset et al ${ }^{96}$., where 
higher BMI was associated with increased risk of depression, but in contrast, they had no strong evidence of an association between BMI and anxiety. ${ }^{96}$ This contrast could be explained through differences in validated subjective questionnaires. Our study used the STAI and BDI-II to determine trait anxiety and depression levels, respectively, whereas this particular study used the Hospital Anxiety and Depression Rating Scale (HADS), a shorter questionnaire consisting of 7

questions for anxiety and 7 for depression, and did not target trait anxiety directly ${ }^{96,97}$ In order to understand trait anxiety and depression, it is important to consider the influence of external factors, such as age and BMI, that may contribute to the severity of mood disorders.

\section{Sleep, Concussion History, Trait Anxiety, and Depression}

The significant indirect pathways between concussion history and trait anxiety and depression with mediation of sleep quality appears to be a novel finding in young adults, which cannot be directly compared to prior research. However, our models suggest that as historical number of concussions increased, sleep quality worsened, which is consistent with previous literature. ${ }^{27,98}$ Individuals with a greater concussion history are at greater risk for experiencing long-term problems in depression, but also changes in sleep patterns as well as tiredness or fatigue. ${ }^{27}$ Poor sleep quality is among the most common grievances after concussion. ${ }^{99}$ The present findings do have a few similarities with Duffield et $\mathrm{al}^{98}$, where high incidence of poor sleep quality may have been related to depressive symptoms, and the number of concussions within their history. ${ }^{98}$ Even though Duffield et al..${ }^{98}$, did not examine these areas collectively, it is important to note the directional relationship of sleep quality and depression, as well as sleep quality and concussion history is consistent with our study. Comparatively, another study found that post-concussion sleep disturbances may predict decrements in mental health, such as symptoms of depression, anxiety, and apathy 1 year post-injury. ${ }^{26}$ While our study examined 
healthy individuals with and without a history of concussion, our findings may serve as a foundational approach for clinicians to consider examining sleep quality and mental health together in individuals with a history of concussion.

\section{Concussion History, Trait Anxiety, and Depression}

Anxiety has been previously examined with concussion, ${ }^{14,44,100}$ but minimal research has targeted trait anxiety with concussion history and should not be overlooked. Evidence has shown that trait anxiety is highly correlated with generalized anxiety ${ }^{101}$ and there has been a study that observed state anxiety with concussion history ${ }^{64}$, but there is an emergency need for a better understanding of trait anxiety with concussions.

Although we did not find a direct relationship with depression and concussion history, a different study found that a history of two or more concussions as compared to a history of no concussions can result in worsening symptoms of depression. ${ }^{27}$ Vynorius et al. ${ }^{27}$ used the BDI-II as well to examine depression in young adults, but in contrast, had a smaller sample size $(\mathrm{n}=84)$ which may have affected the results. ${ }^{27}$ Additionally, a larger nation-wide study ( $\mathrm{n}=8000$ ) found that participants with a greater number of previous concussions reported greater psychological distress, including depression. ${ }^{64}$ Our study had a smaller sample size in comparison, but the studies differed in the use of validated subjective questionnaires and how we group participants based on number of concussions. Weber et al. ${ }^{64}$ used the BSI-18 to assess a portion of anxiety and depression, however, the authors stated that the questionnaire was not designed for this population, ${ }^{64}$ differing from our study where the STAI has been well validated within young adults and previous concussion research ${ }^{44,100}$, as well as the BDI. ${ }^{92,92,102}$

Our models may guide clinicians to recognize and understand mood and sleep disturbances in conjunction with those with a history of concussion, as they may explain the 
collective effects on an individual's quality of life, compared to considering the mood and sleep disturbances separately. A growing body of literature has identified the prevalence of prolonged sleep disturbances with a history of concussion, ${ }^{27,77,79,98}$ but it is important that researchers continue to explore what this might mean with mood disturbances. Our novel findings may help clinicians target sleep disturbances when assessing for those who are at risk of worsened mood disturbances based on their concussion history and not just focus on these elements separately. Furthermore, anxiety, depression, and sleep disturbances are major elements that may be able to shed light on how individuals may respond following concussion, therefore could be included as part of pre-participation screening, but also in the initial assessment of concussion and management of concussion. By considering sleep disturbances with concussion history, clinicians could be able to identify mood disturbances prior to injury, as well as following a concussive event, that may result in prolonged disturbances and may further negatively affect their quality of life. ${ }^{27,63,65,91,92}$

\section{Limitations}

This study is not without its limitations. It should be acknowledged that this survey was conducted during a global pandemic. Recent evidence has shown that Covid-19 has had a negative effect on mental health, as $71.26 \%$ have indicated their stress/anxiety levels have increased during the pandemic. ${ }^{103}$ While we aimed to expand on diversity and inclusion within our sample population, we could have benefitted from more participants with a history of concussions, as well as having more male and non-binary participants from multiple institutions to improve the study's generalizability. This study was conducted through an online survey and although we utilized means to prevent survey fatigue, our survey lasted up to 30 minutes for some individuals and included potential emotionally triggering questions that could negatively 
affect the survey response rate. As with any survey, there was a potential risk of bias due to the subjective nature of the instruments used.

\section{Conclusion}

Concussion history may influence trait anxiety and depression through an indirect path involving sleep quality in healthy young adults. This relationship may require a concomitant consideration of the influence of sleep quality and concussion history associated with trait anxiety and depression. Our preliminary findings demonstrate the importance of examining trait anxiety, depression, and sleep disturbances within individuals with a history of concussion and these components collectively may be important to include as part of baseline screening and in the evaluation and management of concussion.

Understanding this relationship may guide clinicians to better recognize and manage prolonged sleep and mood disturbances that may continue well past recovery and acknowledgement of these disturbances may prevent the long-term consequences that may negatively affect an individual's quality of life. 


\section{REFERENCES}

1. Harmon KG, Clugston JR, Dec K, et al. American Medical Society for Sports Medicine position statement on concussion in sport. Br J Sports Med. 2019;53(4):213-225. doi:10.1136/bjsports-2018-100338

2. Harmon KG, Drezner J, Gammons M, et al. American Medical Society for Sports Medicine Position Statement: Concussion in Sport. Clin J Sport Med. 2013;23(1):1. doi:10.1097/JSM.0b013e31827f5f93

3. Prentice WE. Principles of Athletic Training: A Guide to Evidence-Based Clinical Practice. Sixteenth edition. McGraw-Hill Education; 2017.

4. Craton N, Ali H, Lenoski S. COACH CV: The Seven Clinical Phenotypes of Concussion. Brain Sci. 2017;7(9). doi:10.3390/brainsci7090119

5. Willer B, Leddy JJ. Management of concussion and post-concussion syndrome. Curr Treat Options Neurol. 2006;8(5):415-426. doi:10.1007/s11940-006-00319

6. Clay MB, Glover KL, Lowe DT. Epidemiology of concussion in sport: a literature review. J Chiropr Med. 2013;12(4):230-251. doi:10.1016/j.jcm.2012.11.005

7. Leddy JJ, Sandhu H, Sodhi V, Baker JG, Willer B. Rehabilitation of Concussion and Post-concussion Syndrome. Sports Health. 2012;4(2):147-154. doi: $10.1177 / 1941738111433673$

8. Mantua J, Henry OS, Garskovas NF, Spencer RMC. Mild Traumatic Brain Injury Chronically Impairs Sleep- and Wake-Dependent Emotional Processing. Sleep. 2017;40(6). doi:10.1093/sleep/zsx062 
9. Kennedy JE, Lumpkin RJ, Grissom JR. A Survey of Mild Traumatic Brain Injury Treatment in the Emergency Room and Primary Care Medical Clinics. Mil Med. 2006;171(6):516-521. doi:10.7205/MILMED.171.6.516

10. Association of acute depressive symptoms and functional connectivity of emotional processing regions following sport-related concussion. Accessed May 24, 2020. https://www.ncbi.nlm.nih.gov/pmc/articles/PMC6029562/

11. Kontos AP, Covassin T, Elbin RJ, Parker T. Depression and neurocognitive performance after concussion among male and female high school and collegiate athletes. Arch Phys Med Rehabil. 2012;93(10):1751-1756. doi:10.1016/j.apmr.2012.03.032

12. Ellis MJ, Ritchie LJ, Koltek M, et al. Psychiatric outcomes after pediatric sports-related concussion. J Neurosurg Pediatr. 2015;16(6):709-718. doi:10.3171/2015.5.PEDS15220

13. Kontos AP, Deitrick JM, Reynolds E. Mental health implications and consequences following sport-related concussion. Br J Sports Med. 2016;50(3):139-140. doi:10.1136/bjs ports-2015-095564

14. Sandel N, Reynolds E, Cohen PE, Gillie BL, Kontos AP. Anxiety and Mood Clinical Profile following Sport-related Concussion: From Risk Factors to Treatment. Sport Exerc Perform Psychol. 2017;6(3):304-323. doi: $10.1037 /$ spy0000098

15. Parcell DL, Ponsford JL, Redman JR, Rajaratnam SM. Poor Sleep Quality and Changes in Objectively Recorded Sleep After Traumatic Brain Injury: A 
Preliminary Study. Arch Phys Med Rehabil. 2008;89(5):843-850.

doi:10.1016/j.apmr.2007.09.057

16. Buysse DJ. Insomnia. JAMA J Am Med Assoc. 2013;309(7):706-716. doi:10.1001/jama.2013.193

17. Medic G, Wille M, Hemels ME. Short- and long-term health consequences of sleep disruption. Nat Sci Sleep. 2017;9:151-161. doi:10.2147/NSS.S134864

18. Colten HR, Altevogt BM, Research I of M (US) C on SM and. Extent and Health Consequences of Chronic Sleep Loss and Sleep Disorders. National Academies Press (US); 2006. Accessed July 25, 2020. https://www.ncbi.nlm.nih.gov/books/NBK19961/

19. Institute of Medicine (US) Committee on Sleep Medicine and Research. Sleep Disorders and Sleep Deprivation: An Unmet Public Health Problem. (Colten HR, Altevogt BM, eds.). National Academies Press (US); 2006. Accessed May 17, 2020. http://www.ncbi.nlm.nih.gov/books/NBK19960/

20. Baglioni C, Battagliese G, Feige B, et al. Insomnia as a predictor of depression: a meta-analytic evaluation of longitudinal epidemiological studies. J Affect Disord. 2011;135(1-3):10-19. doi:10.1016/j.jad.2011.01.011

21. Triantafillou S, Saeb S, Lattie EG, Mohr DC, Kording KP. Relationship Between Sleep Quality and Mood: Ecological Momentary Assessment Study. JMIR Ment Health. 2019;6(3). doi:10.2196/12613

22. Difrancesco S, Lamers F, Riese H, et al. Sleep, circadian rhythm, and physical activity patterns in depressive and anxiety disorders: A 2-week ambulatory 
assessment study. Depress Anxiety. 2019;36(10):975-986.

doi:10.1002/da.22949

23. Tkachenko N, Singh K, Hasanaj L, Serrano L, Kothare SV. Sleep Disorders Associated With Mild Traumatic Brain Injury Using Sport Concussion Assessment Tool 3. Pediatr Neurol. 2016;57:46-50.e1. doi:10.1016/j.pediatrneurol.2015.12.019

24. Chaput G, Giguère J-F, Chauny J-M, Denis R, Lavigne G. Relationship among subjective sleep complaints, headaches, and mood alterations following a mild traumatic brain injury. Sleep Med. 2009;10(7):713-716.

doi:10.1016/j.sleep.2008.07.015

25. Oyegbile TO, Dougherty A, Tanveer S, Zecavati N, Delasobera BE. High Sleep Disturbance and Longer Concussion Duration in Repeat Concussions. Behav Sleep Med. 2020;18(2):241-248. doi:10.1080/15402002.2019.1578223

26. Chan LG, Feinstein A. Persistent Sleep Disturbances Independently Predict Poorer Functional and Social Outcomes 1 Year After Mild Traumatic Brain Injury. J Head Trauma Rehabil. 2015;30(6):E67-75. doi:10.1097/HTR.0000000000000119

27. Vynorius KC, Paquin AM, Seichepine DR. Lifetime Multiple Mild Traumatic Brain Injuries Are Associated with Cognitive and Mood Symptoms in Young Healthy College Students. Front Neurol. 2016;7. doi:10.3389/fneur.2016.00188

28. Barkhoudarian G, Hovda DA, Giza CC. The Molecular Pathophysiology of Concussive Brain Injury - an Update. Phys Med Rehabil Clin N Am. 2016;27(2):373-393. doi:10.1016/j.pmr.2016.01.003 
29. Blake AL, McVicar CL, Retino M, Hall EE, Ketcham CJ. Concussion history influences sleep disturbances, symptoms, and quality of life in collegiate student-athletes. Sleep Health. 2019;5(1):72-77. doi:10.1016/j.sleh.2018.10.011

30. Konrad C, Geburek AJ, Rist F, et al. Long-term cognitive and emotional consequences of mild traumatic brain injury. Psychol Med. 2011;41(6):11971211. doi:10.1017/S0033291710001728

31. Fralick M, Thiruchelvam D, Tien HC, Redelmeier DA. Risk of suicide after a concussion. CMAJ Can Med Assoc J. 2016;188(7):497-504.

doi:10.1503/cmaj.150790

32. van der Helm E, Walker MP. Overnight Therapy? The Role of Sleep in Emotional Brain Processing. Psychol Bull. 2009;135(5):731-748. doi:10.1037/a0016570

33. Salzman CD, Fusi S. Emotion, Cognition, and Mental State Representation in Amygdala and Prefrontal Cortex. Annu Rev Neurosci. 2010;33:173-202. doi:10.1146/annurev.neuro.051508.135256

34. Drevets WC, Price JL, Furey ML. Brain structural and functional abnormalities in mood disorders: implications for neurocircuitry models of depression. Brain Struct Funct. 2008;213(1-2):93-118. doi:10.1007/s00429-008-0189-x

35. Pandya M, Altinay M, Malone DA, Anand A. Where in the Brain Is Depression? Curr Psychiatry Rep. 2012;14(6):634-642. doi:10.1007/s11920$012-0322-7$ 
36. Shin LM, Liberzon I. The Neurocircuitry of Fear, Stress, and Anxiety Disorders. Neuropsychopharmacology. 2010;35(1):169-191. doi:10.1038/npp.2009.83

37. Brain Basics: Understanding Sleep | National Institute of Neurological Disorders and Stroke. Accessed May 20, 2020. https://www.ninds.nih.gov/Disorders/patient-caregivereducation/Understanding-sleep

38. Szymusiak R, McGinty D. Hypothalamic regulation of sleep and arousal. Ann N Y Acad Sci. 2008;1129:275-286. doi:10.1196/annals.1417.027

39. Blanco C, Okuda M, Wright C, et al. Mental Health of College Students and Their Non-college-attending Peers: Results from the National Epidemiologic Study on Alcohol and Related Conditions. Arch Gen Psychiatry. 2008;65(12):1429-1437. doi:10.1001/archpsyc.65.12.1429

40. Locke A, Kirst N, Shultz CG. Diagnosis and Management of Generalized Anxiety Disorder and Panic Disorder in Adults. Am Fam Physician. 2015;91(9):617-624.

41. Craske MG, Stein MB, Eley TC, et al. Anxiety disorders. Nat Rev Dis Primer. 2017;3:17024. doi:10.1038/nrdp.2017.24

42. Plaisier I, Beekman ATF, de Graaf R, Smit JH, van Dyck R, Penninx BWJH. Work functioning in persons with depressive and anxiety disorders: The role of specific psychopathological characteristics. J Affect Disord. 2010;125(13):198-206. doi:10.1016/j.jad.2010.01.072 
43. Henning ER, Turk CL, Mennin DS, Fresco DM, Heimberg RG. Impairment and quality of life in individuals with generalized anxiety disorder. Depress Anxiety 1091-4269. 2007;24(5):342-349. doi:10.1002/da.20249

44. Covassin T, Crutcher B, Bleecker A, Heiden EO, Dailey A, Yang J. Postinjury Anxiety and Social Support Among Collegiate Athletes: A Comparison Between Orthopaedic Injuries and Concussions. J Athl Train. 2014;49(4):462468. doi:10.4085/1062-6059-49.2.03

45. Beesdo K, Knappe S, Pine DS. Anxiety and Anxiety Disorders in Children and Adolescents: Developmental Issues and Implications for DSM-V. Psychiatr Clin North Am. 2009;32(3):483-524. doi:10.1016/j.psc.2009.06.002

46. Gottschalk MG, Domschke K. Genetics of generalized anxiety disorder and related traits. Dialogues Clin Neurosci. 2017;19(2):159-168.

47. Franić S, Middeldorp CM, Dolan CV, Ligthart L, Boomsma DI. Childhood and adolescent anxiety and depression: beyond heritability. J Am Acad Child Adolesc Psychiatry. 2010;49(8):820-829. doi:10.1016/j.jaac.2010.05.013

48. McLaughlin KA, Behar E, Borkovec T. Family History of Psychological Problems in Generalized Anxiety Disorder. J Clin Psychol. 2008;64(7):905918. doi:10.1002/jclp.20497

49. Furr SR, Westefeld JS, McConnell GN, Jenkins JM. Suicide and depression among college students: A decade later. Prof Psychol Res Pract. 2001;32(1):97-100. doi:10.1037/0735-7028.32.1.97 
50. Ebert DD, Buntrock C, Mortier P, et al. Prediction of major depressive disorder onset in college students. Depress Anxiety. 2019;36(4):294-304. doi:10.1002/da.22867

51. Belmaker RH, Agam G. Major Depressive Disorder. N Engl J Med. 2008;358(1):55-68. doi:10.1056/NEJMra073096

52. Paluska SA, Schwenk TL. Physical activity and mental health: current concepts. Sports Med Auckl NZ. 2000;29(3):167-180. doi:10.2165/00007256200029030-00003

53. Lorant V, Deliège D, Eaton W, Robert A, Philippot P, Ansseau M. Socioeconomic inequalities in depression: a meta-analysis. Am J Epidemiol. 2003;157(2):98-112. doi:10.1093/aje/kwf182

54. Gujral S, Aizenstein H, Reynolds CF, Butters MA, Erickson KI. Exercise Effects on Depression: Possible Neural Mechanisms. Gen Hosp Psychiatry. 2017;49:2-10. doi:10.1016/j.genhosppsych.2017.04.012

55. Martinsen EW. Benefits of exercise for the treatment of depression. Sports Med Auckl NZ. 1990;9(6):380-389. doi:10.2165/00007256-199009060-00006

56. Farabaugh A, Bitran S, Nyer M, et al. Depression and suicidal ideation in college students. Psychopathology. 2012;45(4):228-234.

doi:10.1159/000331598

57. Pedrelli P, Nyer M, Yeung A, Zulauf C, Wilens T. College Students: Mental Health Problems and Treatment Considerations. Acad Psychiatry J Am Assoc Dir Psychiatr Resid Train Assoc Acad Psychiatry. 2015;39(5):503-511. doi:10.1007/s40596-014-0205-9 
58. Downs MF, Eisenberg D. Help seeking and treatment use among suicidal college students. J Am Coll Health J ACH. 2012;60(2):104-114.

doi:10.1080/07448481.2011.619611

59. McAllister TW, Ford JC, Flashman LA, et al. Effect of head impacts on diffusivity measures in a cohort of collegiate contact sport athletes. Neurology. 2014;82(1):63-69. doi:10.1212/01.wn1.0000438220.16190.42

60. Depue BE, Olson-Madden JH, Smolker HR, Rajamani M, Brenner LA, Banich MT. Reduced Amygdala Volume Is Associated with Deficits in Inhibitory Control: A Voxel- and Surface-Based Morphometric Analysis of Comorbid PTSD/Mild TBI. BioMed Res Int. 2014;2014. doi:10.1155/2014/691505

61. Cho HB, Bueler CE, DiMuzio J, et al. Negative Mood States Correlate with Laterobasal Amygdala in Collegiate Football Players. BioMed Res Int. 2018;2018. doi:10.1155/2018/8142631

62. Chen J-K, Johnston KM, Petrides M, Ptito A. Neural substrates of symptoms of depression following concussion in male athletes with persisting postconcussion symptoms. Arch Gen Psychiatry. 2008;65(1):81-89. doi:10.1001/archgenpsychiatry.2007.8

63. Laforce R, Martin-MaCleod L. Symptom Cluster Associated with Mild Traumatic Brain Injury in University Students. Percept Mot Skills. 2001;93(1):281-288. doi:10.2466/pms.2001.93.1.281

64. Michelle L. Weber, John-Henry L. Dean, Nicole L. Hoffman, Steven P. Broglio, Michael McCrea, Thomas W. McAllister, Julianne D. Schmidt, , April Reed Hoy, Joseph B. Hazzard, Louise A. Kelly, Justus D. Ortega, Nicholas 
Port, Margot Putukian, T. Dianne Langford, Ryan Tierney, Darren E. Campbell, Gerald McGinty, Patrick O’Donnell, Steven J. Svoboda, John P. DiFiori, Christopher C. Giza, Holly J. Benjamin, Thomas Buckley, Thomas W. Kaminski, James R. Clugston, Luis A. Feigenbaum, James T. Eckner, Kevin Guskiewicz, Jason P. Mihalik, Jessica Dysart Miles, Scott Anderson, Christina L. Master, Micky Collins, Anthony P. Kontos, Jeffrey J. Bazarian, Sara P.D. Chrisman, Allison Brooks, Stefan Duma, Christopher Todd Bullers, Christopher M. Miles, Brian H. Dykhuizen Influences of Mental Illness, Current Psychological State, and Concussion History on Baseline Concussion Assessment Performance -2018. Accessed April 21, 2020. https://journals.sagepub.com/doi/abs/10.1177/0363546518765145

65. Koponen S, Taiminen T, Portin R, et al. Axis I and II Psychiatric Disorders After Traumatic Brain Injury: A 30-Year Follow-Up Study. Am J Psychiatry. Published online 2002:7.

66. Ponsford J, Cameron P, Fitzgerald M, Grant M, Mikocka-Walus A, Schönberger M. Predictors of postconcussive symptoms 3 months after mild traumatic brain injury. Neuropsychology. 2012;26(3):304-313. doi:10.1037/a0027888

67. Guskiewicz KM, Marshall SW, Bailes J, et al. Recurrent concussion and risk of depression in retired professional football players. Med Sci Sports Exerc. 2007;39(6):903-909. doi:10.1249/mss.0b013e3180383da5

68. Dretsch MN, Silverberg ND, Iverson GL. Multiple Past Concussions Are Associated with Ongoing Post-Concussive Symptoms but Not Cognitive 
Impairment in Active-Duty Army Soldiers. J Neurotrauma. 2015;32(17):13011306. doi:10.1089/neu.2014.3810

69. Kerr ZY, Evenson KR, Rosamond WD, Mihalik JP, Guskiewicz KM, Marshall SW. Association between concussion and mental health in former collegiate athletes. Inj Epidemiol. 2014;1(1). doi:10.1186/s40621-014-0028-x

70. Carskadon MA, Dement WC. Chapter 2 - Normal Human Sleep : An Overview. $: 21$.

71. Bruce ES, Lunt L, McDonagh JE. Sleep in adolescents and young adults. Clin Med. 2017;17(5):424-428. doi:10.7861/clinmedicine.17-5-424

72. Opp MR, Krueger JM. Sleep and Immunity: A Growing Field with Clinical Impact. Brain Behav Immun. 2015;47:1-3. doi:10.1016/j.bbi.2015.03.011

73. Raikes AC, Schaefer SY. Sleep Quantity and Quality during Acute Concussion: A Pilot Study. Sleep. 2016;39(12):2141-2147. doi:10.5665/sleep.6314

74. Nyer M, Farabaugh A, Fehling K, et al. RELATIONSHIP BETWEEN SLEEP DISTURBANCE AND DEPRESSION, ANXIETY, AND FUNCTIONING IN COLLEGE STUDENTS. Depress Anxiety. 2013;30(9). doi:10.1002/da.22064

75. Benca RM, Obermeyer WH, Thisted RA, Gillin JC. Sleep and psychiatric disorders. A meta-analysis. Arch Gen Psychiatry. 1992;49(8):651-668; discussion 669-670. doi:10.1001/archpsyc.1992.01820080059010

76. Strine TW, Chapman DP. Associations of frequent sleep insufficiency with health-related quality of life and health behaviors. Sleep Med. 2005;6(1):23-27. doi:10.1016/j.sleep.2004.06.003 
77. Gosselin N, Lassonde M, Petit D, et al. Sleep following sport-related concussions. Sleep Med. 2009;10(1):35-46. doi:10.1016/j.sleep.2007.11.023

78. Hoffman NL, O’Connor PJ, Schmidt MD, Lynall RC, Schmidt JD. Relationships between Post-Concussion Sleep and Symptom Recovery: A Preliminary Study. J Neurotrauma. 2020;37(8):1029-1036.

doi:10.1089/neu.2019.6761

79. Hoffman NL, O'Connor PJ, Schmidt MD, Lynall RC, Schmidt JD. Differences in sleep between concussed and nonconcussed college students: a matched case-control study. Sleep. 2019;42(2). doi:10.1093/sleep/zsy222

80. Hoffman NL, Weber ML, Broglio SP, et al. Influence of Postconcussion Sleep Duration on Concussion Recovery in Collegiate Athletes. Clin J Sport Med Off J Can Acad Sport Med. Published online November 16, 2017. doi:10.1097/JSM.0000000000000538

81. Huang T-Y, Ma H-P, Tsai S-H, Chiang Y-H, Hu C-J, Ou J. Sleep Duration and Sleep Quality following Acute Mild Traumatic Brain Injury: A Propensity Score Analysis. Behav Neurol. 2015;2015. doi:10.1155/2015/378726

82. Jackson-Koku G. Beck Depression Inventory. Occup Med. 2016;66(2):174-175. doi:10.1093/occmed/kqv087

83. Smarr KL, Keefer AL. Measures of depression and depressive symptoms: Beck Depression Inventory-II (BDI-II), Center for Epidemiologic Studies Depression Scale (CES-D), Geriatric Depression Scale (GDS), Hospital Anxiety and Depression Scale (HADS), and Patient Health Questionnaire-9 (PHQ-9). Arthritis Care Res. 2011;63(S11):S454-S466. doi:10.1002/acr.20556 
84. JULiAn LJ. Measures of Anxiety. Arthritis Care Res. 2011;63(0 11). doi:10.1002/acr.20561

85. Julian LJ. Measures of anxiety: State-Trait Anxiety Inventory (STAI), Beck Anxiety Inventory (BAI), and Hospital Anxiety and Depression Scale-Anxiety (HADS-A). Arthritis Care Res. 2011;63(S11):S467-S472.

doi:10.1002/acr.20561

86. Mosti C, Spiers MV, Kloss JD. A practical guide to evaluating sleep disturbance in concussion patients. Neurol Clin Pract. 2016;6(2):129-137. doi:10.1212/CPJ.0000000000000225

87. Krystal AD, Edinger JD. Measuring sleep quality. Sleep Med. 2008;9 Suppl 1:S10-17. doi:10.1016/S1389-9457(08)70011-X

88. Buysse DJ, Hall ML, Strollo PJ, et al. Relationships Between the Pittsburgh Sleep Quality Index (PSQI), Epworth Sleepiness Scale (ESS), and Clinical/Polysomnographic Measures in a Community Sample. J Clin Sleep Med JCSM Off Publ Am Acad Sleep Med. 2008;4(6):563-571.

89. de la Vega R, Tomé-Pires C, Solé E, et al. The Pittsburgh Sleep Quality Index: Validity and factor structure in young people. Psychol Assess. 2015;27(4):e22e27. doi:10.1037/pas0000128

90. Bastien $\mathrm{CH}$, Vallières A, Morin CM. Validation of the Insomnia Severity Index as an outcome measure for insomnia research. Sleep Med. 2001;2(4):297-307. doi:10.1016/s1389-9457(00)00065-4 
91. Levin HS, McCauley SR, Josic CP, et al. Predicting Depression Following Mild Traumatic Brain Injury. Arch Gen Psychiatry. 2005;62(5):523-528. doi:10.1001/archpsyc.62.5.523

92. Kontos AP, Covassin T, Elbin RJ, Parker T. Depression and neurocognitive performance after concussion among male and female high school and collegiate athletes. Arch Phys Med Rehabil. 2012;93(10):1751-1756. doi:10.1016/j.apmr.2012.03.032

93. Buysse DJ, Reynolds CF, Monk TH, Berman SR, Kupfer DJ. The Pittsburgh Sleep Quality Index: a new instrument for psychiatric practice and research. Psychiatry Res. 1989;28(2):193-213. doi:10.1016/0165-1781(89)90047-4

94. Dinger MK, Behrens TK, Han JL. Validity and Reliability of the International Physical Activity Questionnaire in College Students. Am J Health Educ. 2006;37(6):337-343. doi:10.1080/19325037.2006.10598924

95. O'Reilly-Shah VN. Factors influencing healthcare provider respondent fatigue answering a globally administered in-app survey. PeerJ. 2017;5. doi: $10.7717 /$ peerj. 3785

96. Bjerkeset O, Romundstad P, Evans J, Gunnell D. Association of Adult Body Mass Index and Height with Anxiety, Depression, and Suicide in the General Population: The HUNT Study. Am J Epidemiol. 2007;167(2):193-202. doi:10.1093/aje/kwm280

97. Bjelland I, Dahl AA, Haug TT, Neckelmann D. The validity of the Hospital Anxiety and Depression Scale. An updated literature review. J Psychosom Res. 2002;52(2):69-77. doi:10.1016/s0022-3999(01)00296-3 
98. Duffield TC, Lim MM, Novak M, et al. The relationship between depressive symptoms, somatic complaints, and concussion history with poor sleep in collegiate athletes. Sleep Health. 2021;7(1):43-48.

doi:10.1016/j.sleh.2020.06.009

99. Mathias JL, Alvaro PK. Prevalence of sleep disturbances, disorders, and problems following traumatic brain injury: a meta-analysis. Sleep Med. 2012;13(7):898-905. doi:10.1016/j.sleep.2012.04.006

100. Turner S, Langdon J, Shaver G, Graham V, Naugle K, Buckley T. Comparison of Psychological Response between Concussion and Musculoskeletal Injury in Collegiate Athletes. Sport Exerc Perform Psychol. 2017;6(3):277-288. doi:10.1037/spy0000099

101. Chambers JA, Power KG, Durham RC. The relationship between trait vulnerability and anxiety and depressive diagnoses at long-term follow-up of Generalized Anxiety Disorder. J Anxiety Disord. 2004;18(5):587-607. doi:10.1016/j.janxdis.2003.09.001

102. Vargas G, Rabinowitz A, Meyer J, Arnett PA. Predictors and prevalence of postconcussion depression symptoms in collegiate athletes. J Athl Train. 2015;50(3):250-255. doi:10.4085/1062-6050-50.3.02

103. Wang X, Hegde S, Son C, Keller B, Smith A, Sasangohar F. Investigating Mental Health of US College Students During the COVID-19 Pandemic: CrossSectional Survey Study. J Med Internet Res. 2020;22(9). doi:10.2196/22817 


\section{APPENDIX A: PITTSBURGH SLEEP QUALITY INDEX (PSQI)}

\section{INSTRUCTIONS:}

The following questions relate to your sleep habits during the past month only. Your answers should indicate the most accurate reply for the majority of days and nights.

Please answer all questions.

1. During the past month, what time have you usually gone to bed at night?

BED TIME

2. During the past month, how long (in minutes) has it usually taken you to fall asleep each night?

NUMBER OF MINUTES

3. During the past month, what time have you usually gotten up in the morning?

\section{GETTING UP TIME}

4. During the past month, how many hours of actual sleep did you get at night? (This may be different than the number of hours you spent in bed.)

HOURS OF SLEEP PER NIGHT

For each of the remaining questions, check the one best response. Please answer all questions.

5. During the past month, how often have you had trouble sleeping because you:

a) Cannot get to sleep within 30 minutes

Not during Less than Once or twice Three or more past month ___ once a week___ a week___ times a week

b) Wake up in the middle of the night or early morning

$\begin{array}{llll}\begin{array}{l}\text { Not during } \\ \text { past month }\end{array} \quad \begin{array}{c}\text { Less than } \\ \text { once a week }\end{array} & \begin{array}{l}\text { Once or twice } \\ \text { a week_ }\end{array} & \begin{array}{c}\text { Three or more } \\ \text { times a week }\end{array}\end{array}$

c) Have to get up to use the bathroom

Not during Less than Once or twice Three or more past month___ once a week ___ a week ___ times a week

d) Cannot breathe comfortably

$\begin{array}{lrcl}\text { Not during } & \text { Less than } & \text { Once or twice } & \text { Three or more } \\ \text { past month } & \text { once a week } & \text { a week } & \text { times a week }\end{array}$


e) Cough or snore loudly

Not during

past month

f) Feel too cold

Not during

past month

g) Feel too hot

Not during

past month

h) Had bad dreams

Not during

past month

i) Have pain

Not during

past month
Less than

once a week

Less than

once a week

Less than

once a week

Less than

once a week

Less than

once a week
Once or twice

a week

Once or twice

a week

Once or twice

a week

Once or twice

a week

Three or more

times a week
Three or more

times a week
Three or more times a week

Three or more times a week

6. During the past month, how would you rate your sleep quality overall?

Once or twice a week

Three or more times a week

Very good

Fairly good

Fairly bad

Very bad

7. During the past month, how often have you taken medicine to help you sleep (prescribed or "over the counter")?
Not during
Less than
Once or twice
Three or more
past month
once a week
a week times a week

8. During the past month, how often have you had trouble staying awake while driving, eating meals, or engaging in social activity?

Not during

past month
Less than

once a week
Once or twice

a week
Three or more

times a week

9. During the past month, how much of a problem has it been for you to keep up enough enthusiasm to get things done?

No problem at all 
Only a very slight problem

Somewhat of a problem

A very big problem

C 1989, University of Pittsburgh. All rights reserved. Developed by Buysse,D.J., Reynolds,C.F., Monk,T.H., Berman,S.R., and Kupfer,D.J. of the University of Pittsburgh using National Institute of Mental Health Funding.

Buysse DJ, Reynolds CF, Monk TH, Berman SR, Kupfer DJ: Psychiatry Research, 28:193-213, 1989 


\section{APPENDIX B: INSOMNIA SEVERITY INDEX (ISI)}

\section{INSTRUCTIONS}

For each question, please CIRCLE the number that best describes your answer.

Please rate the CURRENT (i.e. LAST 2 WEEKS) SEVERITY of your insomnia problem(s).

$\begin{array}{llllll}\text { 1. Difficulty falling asleep } & 0 & 1 & 2 & 3 & 4\end{array}$

$\begin{array}{lllllll}\text { 2. Difficulty staying asleep } & 0 & 1 & 2 & 3 & 4\end{array}$

3.Problems waking up too early $\quad \begin{array}{llllll}0 & 1 & 2 & 3 & 4\end{array}$

4. How SATISFIED/DISSATISFIED are you with your CURRENT sleep pattern?

Very Satisfied Satisfied Moderately Satisfied Dissatisfied Very Dissatisfied

$\begin{array}{lllll}0 & 1 & 2 & 3 & 4\end{array}$

5. How NOTICEABLE to others do you think your sleep problem is in terms of impairing the quality of your life?

Not at all Noticeable A Little Somewhat Much Very Much Noticeable

$\begin{array}{lllll}0 & 1 & 2 & 3 & 4\end{array}$

6. How WORRIED/DISTRESSED are you about your current sleep problem?

Not at all Worried A Little Somewhat Much Very Much Worried

$\begin{array}{lllll}0 & 1 & 2 & 3 & 4\end{array}$

7. To what extent do you consider your sleep problem to INTERFERE with your daily

functioning (e.g. daytime fatigue, mood, ability to function at work/daily chores, concentration, memory, mood, etc.) CURRENTLY?

Not at all Interfering A Little Somewhat Much Very Much Interfering 


\section{APPENDIX C: STATE-TRAIT ANXIETY INVENTORY (STAI) FOR ADULTS}

\section{Sample Items:}

I feel at ease

I feel upset

I lack self-confidence

I am a steady person

Copyright (C) 1968, 1977 by Charles D. Spielberger. All rights reserved in all media. Published by Mind Garden,Inc. www.mindgarden.com 